\title{
COVID-19 Vaccine Hesitancy and Acceptance in a Cohort of Diverse New Zealanders
}

\author{
Kate C. Prickett ${ }^{\mathrm{A}}$, Victoria University of Wellington \\ Hanna Habibi ${ }^{\text {A }}$, Victoria University of Wellington \\ Polly Atatoa Carr ${ }^{\mathrm{B}}$, University of Waikato
}

Word Count: 249 words [abstract], 4,978 words [main text excluding references]

* Corresponding author: kate.prickett@vuw.ac.nz

A. School of Government, Victoria University of Wellington, PO Box 600, Wellington 6140, New Zealand.

B. National Institute of Demographic and Economic Analysis, University of Waikato, Hamilton, New Zealand.

Keywords: COVID-19; Vaccination; Vaccine; Vaccine hesitancy; pandemic; New Zealand. 


\section{Authors' contributions}

Dr. Kate Prickett and Dr. Hanna Habibi conceived of the research question and developed the survey that collected the data. Dr. Habibi cleaned the data and conducted the analyses. Dr. Prickett reviewed the code and analyses. Dr. Prickett, Dr. Habibi, and Dr. Polly Atatoa Carr contributed to the data interpretation. Dr. Prickett developed the first manuscript draft. All authors edited the manuscript, provided a critical review, and approved the final manuscript. Dr. Prickett and Dr. Habibi assessed the underlying data. They take responsibility for the underlying data and analysis accuracy and integrity.

\section{Conflict of interest statement}

The authors declare no conflicts of interest.

\section{Role of funding source}

n/a.

\section{Ethics committee approval}

Human ethics approval (Application ID 0000029123) was granted as a Category B study (low risk) by the Victoria University of Wellington Human Ethics Committee. 


\begin{abstract}
Background: New Zealand's Immunisation Programme is an important pillar in the war against COVID-19, making high vaccine uptake essential. This study sought to: (1) identify potential vaccine uptake rates among New Zealanders prior to programme rollout; (2) understand reasons for unlikelihood/likelihood of vaccine uptake; and, (3) explore sociodemographic differences in these risks.
\end{abstract}

Methods: Data came from a longitudinal study representing a diverse sample of New Zealanders collected in March $2021(n=1,284)$. Multinomial and logit regressions were estimated to examine sociodemographic predictors of vaccine hesitancy and reasons for likelihood/hesitancy.

Findings: $70 \%$ reported they would likely take the vaccine once available. Being younger and less educated were correlated with greater vaccine hesitancy risk. Women were more likely than men to say they were unsure (vs. either likely or unlikely) and to identify concerns regarding personal health, such as potential side effects, as a reason. Men identified concerns surrounding trust in vaccines and the perceived exaggerated risk of COVID-19 to them and the population.

Interpretation: Although a majority intend to take the COVID-19 vaccine once available, a sizeable minority who are more likely to be young, female, and less educated, are unsure about or unlikely to get the vaccine, primarily due to perceptions of unknown future side effects. Ethnicity was not statistically associated with vaccine hesitancy, suggesting that public health efforts aimed at increasing vaccine acceptance among Māori and Pacific peoples - subgroups most at-risk of COVID-19 infection and morbidity-should focus on inequities in health care access to increase uptake.

Funding: n/a. 


\section{Research in context}

\section{Evidence before this study:}

While an extant amount of survey data and literature exists to monitor the COVID-19 vaccine rollout and vaccine hesitancy in developed countries that are most impacted by the COVID19 pandemic, there appears scant evidence on potential vaccine uptake in New Zealand-a country that had yet to make vaccines available to the general population and where there was minimal community transmission of the virus.

We searched in PubMed and Google Scholar for studies using data collected in New Zealand, including terms such as "COVID-19 vaccine", "New Zealand vaccine hesitancy" and "COVID-19 New Zealand." In addition, we went directly to New Zealand's Ministry of Health website - the government institution responsible for New Zealand's COVID-19 Immunisation Programme - for information on surveying conducted by or on behalf of the Ministry. Given the limited number of empirical studies on potential COVID-19 vaccine uptake in New Zealand, we considered all publications, regardless of peer-review status. Prior studies on COVID-19 vaccine uptake in New Zealand included in our review of the existing literature relied on social science research marketing panels that, while diverse, may not necessarily be representative of the New Zealand. Despite different time periods for data collection and analytical samples being derived from different panels, there was consistency across these studies in terms of estimated vaccine uptake, ranging from $69-74 \%$.

\section{Added value of this study:}

To our knowledge, this is the first study that assesses COVID-19 vaccine hesitancy in New Zealand in a multivariate framework, simultaneously assessing a range of sociodemographic predictors to understand the relative importance of these different factors, such as gender, ethnicity, and age. In line with bivariate results from prior studies, we find that young people and those with less education were less likely to say they would take the vaccine. In contrast to prior studies, however, in a multivariate framework identifying as Māori or Pacific was no longer statistically associated with vaccine hesitancy, with population characteristics of these ethnic subgroups (primarily, being younger and less educated) accounting for the bivariate associations. We also find that women were more likely than men to be unsure they would take the vaccine, whereas men were more definitive in terms of both being more unlikely or likely to take the vaccine than being unsure - a finding masked by different vaccine hesitancy measurement in prior studies.

Importantly, the data were collected just two-months prior to the nationwide COVID-19 Immunisation Programme rollout, representing a more temporal examination of vaccine hesitancy, and examines both reasons why people are likely or unlikely to take the vaccine once it becomes available to them.

\section{Implications of all the available evidence:}

The available evidence on COVID-19 vaccine hesitancy in New Zealand's adult population is clear that a majority of New Zealanders are likely to take the COVID-19 vaccine once it becomes available to them. There is consistently, however, approximately $30 \%$ of the population who are still unsure or unlikely to take the vaccine. These people tend to be younger and less educated, suggesting a target group for public health promotions aimed at increasing confidence in the vaccine. Importantly, our findings suggest that public health focus on perceived hesitancy in the Māori and Pacific populations - subgroups that are particularly at-risk of COVID-19 infection and morbidity-may be misplaced. Instead, public health efforts should focus on combating the known inequities in health care access that may increase the risk that vaccine intention among these groups does not translate into uptake. 
One of the key public health tools in the fight against COVID-19 is an effective vaccination programme. Effectiveness means achieving high uptake among the general adult population, ideally sufficient to generate local herd-immunity. ${ }^{1}$ Effectiveness also means equitable access, acceptability and delivery so as to avoid disparities in care and disease outcomes. ${ }^{2}$ New Zealand's COVID-19 elimination strategy has been one of the most effective responses to the pandemic in the world, ${ }^{3}$ resulting in a low number of communitytransmitted infections and 26 deaths since the beginning of the pandemic. ${ }^{4}$ Given this strategy, however, widespread COVID-19 vaccine acceptance is an essential element for relaxing border controls and other strict public health measures that aim to stop community transmission, such as intermittent lockdowns. ${ }^{5}$

New Zealand's COVID-19 Immunisation Programme plans to vaccinate the entire adult population (16 years and over) with the two-dose Pfizer/BioNTech vaccine. A fourstage approach beginning in February 2021 rolled out vaccines first to border and Managed Isolation Quarantine (MIQ) facility workers and those in their households, followed by other high-risk frontline workers. It is anticipated (at the time this article is written) that vaccination among the general population will roll out in May 2021 to those at high-risk of getting very sick from COVID-19 and July 2021 to the general population. ${ }^{6}$

A significant threat to the Immunisation Programme and the health of New Zealanders is low COVID-19 vaccine uptake. For populations in other countries with high rates of COVID-19 transmission and mortality and longer restrictions on freedom of movement, such as the United States and United Kingdom, the path to herd immunity through vaccination is important for returning to pre-pandemic freedoms. Given New Zealand's relatively pre-pandemic-like normalcy (apart from restricted international travel and migration), this context could potentially decrease the motivation or urgency to be vaccinated. Indeed, in a recent survey (17-21 March 2021) approximately $94 \%$ of the UK adult population had positive vaccine sentiment. ${ }^{7}$ In the US, where the COVID-19 response has been politically polarising, ${ }^{8}$ the Kaiser Family Foundation COVID-19 Vaccine Monitor (March 15-22 2021) reported only 13\% of adults said they will definitely not get the vaccine. ${ }^{9}$ In both countries, vaccine hesitancy rates have been declining over time.

In contrast, there is limited understanding of COVID-19 vaccine hesitancy in New Zealand. A research factsheet from the Ministry of Health using data collected between March 26 and April 12021 noted that likelihood of vaccine uptake has remained consistent with prior estimates, with approximately $69 \%$ of the adult population likely to take the COVID-19 vaccine once it becomes available to them. ${ }^{10}$ This proportion aligns with more 
thorough research for the Ministry of Health from data collected in both September and December 2020, although there were signs that people were becoming less certain that they would take the vaccine over time and that certainty may be unequal within important population subgroups. ${ }^{11}$ Women, younger people, and Māori (Indigenous New Zealanders; $17 \%$ of the population ${ }^{12}$ ) and Pacific peoples (those from or with ancestry from islands in the Pacific region; $8 \%$ of the population ${ }^{12}$ ) reported higher rates of vaccine hesitancy. These patterns are cause for greater concern, especially among Māori and Pacific, who face higher risks from COVID-19 disease, ${ }^{13}$ and which are situated within the context of broader preexisting patterns of inequitable access to health care and in health outcomes generally, ${ }^{14-17}$ and in vaccination coverage, specifically. ${ }^{18,19}$

Reasons for COVID-19 vaccine hesitancy most often included concerns around the vaccine's safety and potential side effects. ${ }^{11}$ Given increases in misinformation and conspiracy theories regarding COVID-19 vaccination in recent months ${ }^{20}$ and a majority of New Zealanders indicating they get some information about COVID-19 vaccine from social media $^{11}$ — an environment full of conspiracy theories - it is important to gauge how these hesitancy rates may have changed leading up to vaccine roll-out, and therefore, how the strategy must adapt to support the COVID-19 elimination strategy and avoid exacerbating health inequities.

Moreover, these recent studies have focused on the negative reasons why people are unlikely to get the vaccine and have not focussed on the positive reasons why one might take the vaccine, which may be just as salient from a public policy perspective. For example, one study using from data collected between June-July 2020 found that the most common reasons New Zealanders would be vaccinated were to protect themselves $(62 \%)$ and their family (62\%), to avoid getting seriously ill (52\%), and to feel safe around other people (51\%). People were less likely to report they would get the vaccine because their doctor recommended it $(23 \%){ }^{21}$

To address these gaps, this study examines vaccine hesitancy and acceptability among a diverse sample of New Zealanders $(n=1,282)$ just prior to the May 2021 nationwide COVID-19 Immunisation Programme rollout to the general population. Further, the study leverages rich sociodemographic data to examine who is most likely to take the vaccine once it becomes available. Importantly, this study examines not just the reasons why some are vaccine hesitant, but also the reasons why others are likely to get the vaccine. Understanding this reasoning can point to sources of health resilience within the COVID-19 elimination strategy, and can ensure that a comprehensive vaccination programme includes opportunities 
to maximise access to, confidence in, and motivation to vaccinate among the general population and important sub-groups. Moreover, in a globalised world the findings can provide insight into vaccine promotion and the translation from vaccination intention to access among populations least exposed to the detrimental health ramifications and public health measure impacts during pandemics, but whose willingness to be vaccinated is important for global success in defeating viruses and infectious disease.

\section{METHODS}

Data and sample. Data come from the Life in Lockdown survey, a longitudinal data collection effort that aimed to examine the impact of the nationwide Alert Level 4 lockdown (March-April 2020) on New Zealanders' economic and social wellbeing. ${ }^{22}$ The web-based, self-administered survey was designed by researchers at the Roy McKenzie Centre for the Study of Families and Children and the Institute for Governance and Policy Studies at Victoria University of Wellington, and administered by Colmar Brunton-a social research firm. Respondents were contacted via email through a diverse, existing sampling frame of over 100,000 New Zealanders. In Wave 1, respondents were screened by gender, age, income, region, and ethnicity to ensure a socio-demographically-diverse sample.

Data were collected in April 2020 (Wave 1; $n=2,002$ ) when New Zealand was in its strictest lockdown stage (Alert Level 4), in July 2020 when the country was back in its most relaxed stage (Level 1; Wave 2; $n=1,466 ; 73 \%$ of Wave 1 respondents), and one year later in March 2021 when New Zealand was also in Alert Level 1 (Wave 3; $n=1,310 ; 65 \%$ of Wave 1 respondents). COVID-19 vaccine uptake questions were only asked at Wave 3. The final analytical sample consists of 1,284 respondents aged 18 years and older who participated in Wave 3 of the study (dropping 692 who exited the study by Wave 3). Those who exited the study were more likely to be male and younger than those who remained. Respondents who did not answer the question on vaccine hesitancy or preferred not to say $(n=23)$ were also dropped. Three respondents who identified as gender diverse were excluded because of multicollinearity issues in the models.

Variables. The key outcome variables were likelihood of and reasons for COVID-19 vaccine uptake or hesitancy. These questions were only asked at Wave 3 (March 2021) and were consistent with the Opinions and Lifestyle Survey, a weekly survey conducted in Great Britain during the COVID-19 pandemic ${ }^{23}$ and the Understanding Society survey, a UK household longitudinal study. ${ }^{24}$ To measure vaccine hesitancy, respondents were asked "How likely are you to get vaccinated for the coronavirus (COVID-19) once the vaccine is available to you?", with response options including Very unlikely, Somewhat unlikely, Unsure, 
Somewhat likely, and Very likely. Respondents were also able to indicate whether they had already received the vaccine (no one in this sample) or prefer not to say ( $n=8$; excluding from the analytical sample).

Respondents who indicated that they were unlikely or unsure if they would take the vaccine were given a list of potential reasons, including the option to specify non-listed reasons, for why they were unlikely to take the vaccine. Respondents who chose more than one reason were subsequently asked to identify the most important reason of those that they selected. Symmetrically, respondents who indicated they were likely to take the vaccine were asked a similarly structured series of questions, where they were asked to identify the reasons why they were likely to take the vaccine.

We explore differences in vaccine hesitancy across a range of sociodemographic characteristics that may influence uptake, including those previously shown to be associated with vaccine hesitancy (e.g., age, gender, ethnicity, education), and also other potential variables that tap into people's social support (e.g., household structure), environments (e.g., work status), and potential virus exposure (e.g., region). These variables were collected across the study waves. Sociodemographic characteristics collected at Wave 1 included: age (coded into three dummy variables indicating respondent aged 18-34 years; 35-64 years; or 65 years and older); gender $(1=\text { female })^{\mathrm{i}}$; ethnicity (mutually-exclusive dummy variables indicating New Zealand European/Pākehā; Māori; Pacific; Asian; Other ethnicity (predominately Indian) $)^{\mathrm{ii}}$; and educational attainment (three dummy variables indicating primary/secondary school education; diploma; or university/postgraduate degree); Nativity ( 1 $=$ New Zealand born) was captured in Wave 2. Respondents' annual household income (series of dummy variables ranging from household incomes at $\mathrm{NZ} \$ 30,000$ per annum or less through to over NZ\$150,000), household structure (two parents with dependent children; single parent; living alone; partnered with no dependent children; some other living arrangement), work status (employed; unemployed; not in the labour force), and region (10 dummy variables) ${ }^{\text {iii }}$ were captured at Wave 3.

Analyses. We examined vaccine hesitancy and reasons for hesitancy or uptake using both a bivariate and multivariate approach. Multinomial logistic regressions were used to

\footnotetext{
${ }^{\mathrm{i}}$ We do not report results for the three respondents who identified as gender diverse.

ii Respondents were able to select multiple ethnicities, which were then recoded in prioritised, mutuallyexclusive categories in the following order: Māori, Pacific; Asian; NZ European/Pākeha; Other ethnicities. iii Regions with large urban centres were more likely to have Managed Isolation Quarantines facilities, and hence, higher risk of COVID-19 transmission into the community. In particular, Auckland city was most impacted, experiencing three additional regional lockdowns in response to community transmission from infections in MIQ during the year since the nationwide lockdown (March-April 2020).
} 
assess competing risks between being unlikely, unsure, or likely to get the vaccine. A series of logit regressions were used to predict the odds of identifying specific reasons why or why not respondents would get the vaccine. All analyses were conducted in Stata. Multiple imputation was used for the small amount of item-level missing data on five independent variables $(<1.0 \%$ of analytical data), with 100 imputed datasets analysed through the suite of mi estimate commands. Weights were applied to the bivariate statistics that adjusted to population proportions for age, gender, income, region, and household structure.

\section{RESULTS}

\section{COVID-19 vaccine hesitancy and uptake likelihood}

Table 1 presents COVID-19 vaccine hesitancy for the total sample and across key sociodemographic characteristics. Overall, $70.7 \%$ of the sample indicated they were very likely $(56.0 \%)$ or somewhat likely $(14.8 \%)$ to take the vaccine once it became available to them - a proportion in line with those reported in a December 2020 report (69\%). ${ }^{11}$ Of the $14.2 \%$ that were unlikely to take the vaccine, $9.6 \%$ said they were very unlikely and $4.6 \%$ said they were somewhat unlikely. A further $15.1 \%$ said they were unsure.

Examining key sociodemographic characteristics, younger people were less likely to report that they were likely to take the vaccine $(65.0 \%$ of $18-34$ year olds vs. $70.3 \%$ of $35-64$ year olds and $79.9 \%$ of those 65 years and older). Men were more definitive in their likelihood of vaccine uptake. Although women were slightly less likely to say they would take the vaccine (70.0\% vs. $71.5 \%$ among men), men were also more likely to report being unlikely to take the vaccine (16.3.9\% vs. $12.3 \%$ among women). A greater share of women reported being unsure (17.7\% vs. $12.2 \%$ among men).

Respondents who identified as Māori were least likely to report they would likely take the vaccine (64.8\% vs. $70.7 \%$ among the total sample) and most likely to report they would be unlikely to take the vaccine ( $21.5 \%$ vs. $14.2 \%$ among the total sample). There were statistically similar rates of likelihood and unlikelihood of vaccine uptake among the remaining ethnic groups. A greater share of those born overseas reported they would likely take the vaccine $(72.3 \%$ ) compared to those born in New Zealand (69.8\%).

Those with undergraduate or postgraduate degrees were most likely to report they would likely take the vaccine $(77.8 \%$ vs. $66.3 \%$ and $66.2 \%$ among those with only primary/secondary school education or a post-secondary education diploma, respectively). Higher income households were more likely to report vaccine uptake and less likely to report they would be unlikely to take the vaccine compared with lower income households. 
Table 2 tests the robustness of these bivariate associations using multinomial logistic regression models to identify which associations remain significant predictors of vaccine hesitancy, net of other sociodemographic factors. In line with the bivariate findings, age was statistically associated with vaccine hesitancy, with those aged 18-34 years more than twice as likely at risk of being unlikely to take the vaccine (vs. likely) compared to older age groups. This younger age group was more than three times more likely at risk of saying they were unsure they would take the vaccine (vs. likely) compared to those 65 years and older. Those aged 45-64 years were over twice as likely to be at risk of saying they were unsure if they would take the vaccine (vs. likely) compared to those 65 years or older.

Women were not statistically different to men in their risk of being unlikely to receive the vaccine versus being likely, net of other sociodemographic characteristics. Women, however, were more likely to be unsure they would get the vaccine compared with men. Women were $58.0 \%$ greater risk of being unsure versus likely to get the vaccine compared with men, but also twice as likely of being unsure than unlikely to get the vaccine compared with men. Taken together, men were as likely as women to be at risk of saying they were unlikely to get the vaccine, whereas women were more likely to be unsure.

Higher educational attainment was strongly related to being likely to take the vaccine. Those without university or postgraduate degrees were most at risk of being unlikely to get the vaccine, with those with a primary/secondary school qualification only being 1.8 times and those with a post-secondary diploma 2.5 times at greater risk of being unlikely to take the vaccine (vs. likely). Those without university/postgraduate degrees were also at greater risk of being unsure than likely. On the other hand, whereas household income did not appear to be correlated with risk of being unlikely to receive the vaccine (vs. likely), lower income households were at twice the risk of being unsure they would take the vaccine (vs. likely) compared with higher income households (over NZ\$100,000 per annum).

In the regression models there was no statistical differences across ethnic groups in risk of vaccine hesitancy. Differences between Māori and NZ European/Pākehā were not significant at traditional levels $(p<.05)$.

Reasons for vaccine hesitancy

Among those who were unsure or unlikely to take the COVID-19 vaccine, $40.1 \%$ selected just one reason, $24.8 \%$ selected two reasons, $14.6 \%$ gave three reasons, and a further $11.8 \%$ offered four or more reasons. The remaining $8.7 \%$ offered no explicit reason. ${ }^{\text {iv }}$

\footnotetext{
${ }^{\text {iv }}$ Full set of results presented in Table A1 in the appendix.
} 
Figure 1 displays the reasons why respondents were unlikely to or unsure about receiving the COVID-19 vaccine. The primary concerns were potential unknown long-term effects (63.7\% of vaccine hesitant respondents), followed by those were concerned about the side effects (46.7\%), and those who thought their chances of becoming seriously ill if they caught COVID-19 were low (16.2\%). Very few respondents cited being protected by herd immunity (3.0\% of those unlikely or unsure; 15 people), not having time (1.0\%; five people), or being advised by a health or medical professional to not get the vaccine $(0.21 \%$; one person) as a reason.

Respondents were also asked, of the reasons they identified, which was the most important reason. The pattern of results were similar to when respondents were asked to select any number of reasons - that is, reasons that a larger proportion of respondents suggested was influencing their vaccine hesitancy were also more likely to be selected as the most important reason. Worried about unknown future effects of the vaccines was most often listed as the most important reason, with close to half (48.2\%) of respondents selecting this reason, followed by being worried about the side effects (15.6\%).

Several key findings emerged when estimating a series of logit regressions to examine the association between key sociodemographic characteristics and reasons for being unlikely or unsure of taking the vaccine (Figure 2). ${ }^{\mathrm{v}}$ First, women were more likely than men to report reasons related to the potential impact of the vaccine on their health, with women close to three times more likely to say they were worried about unknown future effects of the vaccine and 1.5 times more likely to say they were worried about vaccine's side effects (albeit significant at $p<.10$ ). Women were less likely than men to say they did not trust vaccines, that the chances were low they would become seriously unwell if they caught COVID-19, and that the impact of COVID-19 was being greatly exaggerated.

People aged between 18-34 years and 35-64 years were between 2.8 and 3.0 times, respectively, more likely to report they were worried about unknown future vaccine effects than people aged 65 and older. Māori and those from the 'Other' ethnic group (predominately Indian) were half as likely as Pākehā/New Zealand Europeans and Pacific to cite unknown future vaccine effects as a reason for being unlikely or unsure of getting the vaccine. Reasons for likelihood of COVID-19 vaccine uptake

Those were reported they were likely to take the COVID-19 vaccine were more likely than vaccine hesitant respondents to cite multiple reasons for their choice. This was despite

\footnotetext{
${ }^{v}$ Full set of results presented in Table A2 in the appendix.
} 
potential vaccine takers having fewer response options available to select than vaccine hesitant respondents. A small majority (51.0\%) of likely vaccine takers selected four reasons or more, $12.2 \%$ selected three reasons, $9.3 \%$ selected two reasons, and $25.5 \%$ selected one reason. Two percent gave no reason. ${ }^{\mathrm{vi}}$

Figure 2 displays the reasons why respondents were likely to receive the vaccine. Close to three-quarters of respondents $(72.6 \%)$ cited they wanted to prevent catching COVID-19 or getting very ill from it and two-thirds (66.1\%) identified protecting others from catching COVID-19. Another 56.0\% said to help their community get back to normal and $53.5 \%$ cited that they would get the vaccine because it would not work unless most people in New Zealand got the vaccine. Among those who selected 'other' and gave a reason (3.3\%), the majority noted the ability to travel as being important in their decision.

When asked to identify the most important reason why they were likely to take the vaccine, there was more variability in responses among those likely to get the vaccine than those who were not. Close to 4 in 10 (39.4\%) of likely vaccine takers said the most important reason influencing them to get the vaccine was to stop them from catching COVID-19 or getting very ill if they caught it. Protecting other people from catching COVID-19 and the vaccine not working unless most people in New Zealand got it were both identified as the most important reason by $17.0 \%$ of the sample. Helping the community get back to normal was identified by $8.8 \%$ of the sample as being the most important reason for getting the vaccine.

Examining the associations between key sociodemographic characteristics and reason for being likely to take the COVID-19 vaccine through a series of logit regression models, age, gender, ethnicity, education, and income all were significant predictors. ${ }^{\text {vii }}$ Those aged 18 -34 years (Odds ratio $[O R]=0.38 ; p<.01)$ and 35-64 years $(O R=0.59 ; p<0.10)$ were less likely to report that a reason for getting the vaccine was to stop them from catching or getting very ill from COVID-19 compared to those 65 years and older. Those 35-64 years were also half as likely to report that they took the vaccines offered to them $(O R=0.50 ; p<$ .01) compared to those 65 years and older. Women were more likely than men to report that allowing their social and family life to get back to normal $(O R=1.36 ; p<.05)$, helping protect others from catching COVID-19 $(O R=1.71 ; p<.001)$, and taking vaccines recommended to them $(O R=1.45 ; p<.05)$ as reasons for getting the vaccine once available.

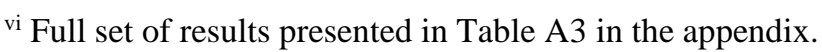

${ }^{\text {vii }}$ Full set of results presented in Table A4 in the appendix.
} 
Those who identified as Asian were less likely than other ethnicities to report all but one of the reasons - to help allow their social and family life to get back to normal-for getting the vaccine. There were few significant differences in reasons for receiving the vaccine among other ethnic groups.

Those with university/postgraduate degrees were more likely than those without university/postgraduate degrees to cite most reasons, with one exception: there were no education differences in identifying "taking vaccines that are recommended" as a reason. Similarly, those in the highest income bracket (household incomes over NZ\$150,000 per annum) were more likely than lower income brackets to identify helping allow their social and family life get back to normal, helping allow their community get back to normal, and that the vaccine won't work unless most people in New Zealand get it as reasons they would likely get the vaccine. There were few income differences in identifying "to stop me catching COVID-19 or getting very ill from it," "to help protect others from catching COVID-19," and taking the vaccines recommended to them as reasons for likely getting the vaccine.

\section{DISCUSSION}

The success of New Zealand's elimination strategy in curbing the impact of COVID19 on population health and reopening New Zealand's international borders is contingent on high and equitable uptake of the COVID-19 vaccine. This study aimed to examine New Zealanders' intended likelihood of receiving the vaccine in the lead up to the rollout to the general population, targeted to begin in May 2021 for adults at high-risk of getting very sick from COVID-19 disease and in July 2021 for the rest of the adult population. In addition, this study examined sociodemographic correlates of intended vaccination as well as the reasons why and why not people were likely to get the vaccine. Several key findings emerged.

In line with prior studies on New Zealanders' COVID-19 vaccine hesitancy, 71\% of respondents said they were either very likely or somewhat likely to take the vaccine once it became available. This rate of vaccine likelihood was consistent despite data for this study being collected in mid-to-late March just after concerns around potential increased risk of blood clots from the AstraZeneca vaccine saw multiple European countries suspend their vaccination programme. ${ }^{25}$ Again, consistent with prior New Zealand research, bivariate associations between individual sociodemographic characteristics and vaccine likelihood showed that younger people, women, and those who identified as Māori were less likely to report they would get the vaccine, whereas those with higher educational attainment and higher household incomes were more likely to report they would be getting the vaccine. 
Importantly, however, several of these associations attenuated once they were examined in a multivariate framework. In this model, net of other sociodemographic variables, Māori were no longer at greater risk of vaccine hesitancy, compared to other ethnic groups. Thus, it is likely that other sociodemographic characteristics that are overrepresented in the Māori population (vs. the general population) account for much of the disparity regarding vaccine hesitancy seen in the initial bivariate findings. Namely, the Māori population is younger, has lower levels of educational attainment, and is underrepresented among the highest income bracket —all factors that appear to have stronger correlations with vaccine hesitancy than ethnicity once examined simultaneously.

This finding is important because ensuring that the components of a comprehensive COVID-19 vaccination strategy are appropriately targeted and do not exacerbate health inequities is critical for programme effectiveness. These results do not negate the need to counter vaccine hesitancy, nor the need for a Māori-focused and-led approach to COVID-19 vaccination. Inequities in vaccination delivery are consistent and compelling in New Zealand with Māori and Pacific rates of vaccination delivery and timeliness in childhood consistently lower than non-Māori, non-Pacific. ${ }^{26,27}$ In childhood, this lower vaccination delivery has also been demonstrated to reflect poor access to vaccination rather than parental intentions to vaccinate their children. ${ }^{28}$ The broader literature has demonstrated that equitable health care delivery for Māori (and Pacific), such as with the immunisation programme, will require Māori governance and leadership, culturally-responsive health care delivery, resourcing of trusted community providers, and supports for access. ${ }^{29-32}$ It is known that the current primary health care system in New Zealand fails to deliver on these points, and fails to meet legal obligations to Māori. ${ }^{33}$ Ongoing attention needs to be paid to the critical combination of heightened risk of mortality and morbidity from COVID-19 disease for Māori (and Pacific) populations ${ }^{13}$ and the systemic racism within New Zealand's health system that will result in inability to translate rates of vaccination intention into vaccine access and uptake. ${ }^{34}$

While the findings suggest that there are no or negligible ethnic differences in people's trust and understanding of the importance of getting the vaccine, these findings, and their implications, are consistent with the success of Māori community-led responses that went beyond government initiatives and policies aimed at preventing the spread of COVID19-for example, the establishment of community-based lockdown roadblocks and trialling new contact tracing technologies such as Bluetooth cards. ${ }^{35-38}$

Another important finding was that women were slightly less likely to say they would get the vaccine than men, however this disparity was driven primarily by women saying they 
were "unsure" they would not get it (17.7\% vs. $12.2 \%$, respectively). Indeed, men were more likely to report that they were very unlikely than women. While prior research has noted women are less likely to say they would get the vaccine, the disparity between our findings and prior research may be driven by the inclusion of an "unsure" category in the middle of the scale, which seems to better reflect women's intention to get the vaccine than being confined to "somewhat or very unlikely" or "somewhat or very likely" (with "don't know" and "not really sure" outside the Likert scale). In sum, women appear less definitive in terms of being unlikely to get the vaccine and may be more easily nudged towards taking the vaccine.

Gender also appeared to be significantly associated with different reasons for vaccine hesitancy. Women were more likely than men to identify potential risks to their personal health, such as unknown future vaccine effects or potential side effects as reasons for being unlikely to receive the vaccine, whereas men were more likely to report broader concerns around the trustworthiness of vaccines generally, being confident they would not get seriously ill should they contract COVID-19, and that the pandemic has been exaggerated.

Finally, people who reported they were likely to get the vaccine were, on average, more likely to identify multiple reasons for their decision, compared to the average number of reasons identified among those unlikely to get the vaccine. Moreover, the most important reason cited was also more heavily concentrated in the most popular reason among those unlikely to get the vaccine. For example, $48 \%$ who were unsure/unlikely they would get the vaccine said the most important reason was because of worry about unknown future vaccine effects. The most important reason was more dispersed among likely vaccine takers with 39\% selecting the most popular reason (to stop them from catching COVID-19 or getting very ill) as also the most important reason. Taken together, this suggests there are wide range of positive benefits that can be employed to demonstrate the utility of the vaccine to those who are currently hesitant, in addition to efforts around dispelling fears around vaccine safety and science.

This study has several limitations. First, while the study sample is sociodemographically diverse and our estimates of COVID-19 vaccine hesitancy are in line with existing New Zealand studies, the findings may not necessarily be extrapolated to the general population. Indeed, by virtue of being an online survey, participants must have access to an electronic device and the internet and, hence, are likely slightly more advantaged. Second, there may be important differences among subgroups that cannot be examined because of statistical power, for example, those who are both Māori and young. Third, the 
findings are correlational not causal. There are likely variables that not included in the models or factors that are unmeasurable that explain some of the significant associations.

Overall, a majority of New Zealand adults are likely to take the COVID-19 vaccine when the Immunisation Programme opens to the general population. There remains, however, a sizeable proportion who are unsure about or unlikely to take the vaccine. Public health initiatives should promote the safety and science of the vaccine, message that individual uptake increases the vaccine's efficacy for the whole community, and have a particular focus on younger and less educated populations. Moreover, public health efforts will need to combat known inequities in health care access that may increase the risk that vaccine intention does not translate into uptake among subgroups, such as Māori and Pacific, who are at heightened risk of COVID-19 infection and morbidity. 


\section{REFERENCES}

[1] Schaffer DeRoo S, Pudalov N, Fu L. Planning for a COVID-19 Vaccination Program. JAMA 2020; 323: 2458-2459.

[2] Tugwell P, de Savigny D, Hawker G, Robinson V. Applying clinical epidemiological methods to health equity: the equity effectiveness loop. BMJ 2006; 332: 358-361.

[3] Baker M, Wilson N, Anglemyer A. Successful Elimination of Covid-19 Transmission in New Zealand. New England Journal of Medicine 2020; 383: e56.

[4] New Zealand: WHO Coronavirus Disease (COVID-19) Dashboard With Vaccination Data. World Health Organization, 2021. https://covid19.who.int/region/wpro/country/nz (accessed 8 May 2021).

[5] Bloomfield, A. COVID-19, 20, 21: lessons from New Zealand's 2020 response for 2021 and beyond. The New Zealand Medical Journal 2021; 134: 1175-8716.

[6] Ministry of Health NZ. Our COVID-19 vaccine rollout plan. Ministry of Health NZ. 2021.

[7] Coronavirus and vaccine hesitancy, Great Britain - Office for National Statistics. Ons.gov.uk. 2021.

https://www.ons.gov.uk/peoplepopulationandcommunity/healthandsocialcare/healtha ndwellbeing/bulletins/coronavirusandvaccinehesitancygreatbritain/17februaryto14mar ch2021 (accessed 2 May 2021).

[8] Funk C, Tyson A. Growing Share of Americans Say They Plan To Get a COVID-19 Vaccine - or Already Have. Pew Research Center Science \& Society. 2021.

[9] Hamel L, Lopes L, Kearney A, Brodie M. KFF COVID-19 Vaccine Monitor: March 2021. San Francisco, CA: Kaiser Family Foundation. 2021. https://www.kff.org/coronavirus-covid-19/poll-finding/kff-covid-19-vaccine-monitormarch-2021/ (accessed 2 May 2021).

[10] Ministry of Health NZ. At a glance: COVID-19 vaccine research insights. Ministry of Health NZ. 2021.

[11] Horizon Research. covid-19 vaccine report. Ministry of Health NZ, 2020 https://www.health.govt.nz/system/files/documents/pages/horizon_research_covid19_vaccine_report_december_2020_final.pdf (accessed 12 May 2021).

[12] Stats NZ. Ethnic group summaries reveal New Zealand's multicultural make-up. Wellington: Stats NZ, 2021.

[13] Steyn N, Binny R, Hannah K, Hendy S, James A, Kukutai T, et al. Estimated inequities in COVID-19 infection fatality rates by ethnicity for Aotearoa New Zealand. The New Zealand Medical Journal 2021; 133: 1175-8716.

[14] Graham R, Masters-Awatere B. Experiences of Māori of Aotearoa New Zealand's public health system: a systematic review of two decades of published qualitative research. Australian and New Zealand Journal of Public Health 2020; 44: 193-200.

[15] Marriott L, Sim D. Indicators of Inequality for Māori and Pacific People. The Journal of New Zealand Studies 2015. DOI:10.26686/jnzs.v0i20.3876.

[16] Minister of Health. New Zealand Health Strategy: Future direction. Wellington: Ministry of Health NZ, 2016 
https://www.health.govt.nz/system/files/documents/publications/new-zealand-healthstrategy-futuredirection-2016-apr16.pdf (accessed 12 May 2021).

[17] Palmer S, Gray H, Huria T, Lacey C, Beckert L, Pitama S. Reported Māori consumer experiences of health systems and programs in qualitative research: a systematic review with meta-synthesis. International Journal for Equity in Health 2019; 18. DOI:10.1186/s12939-019-1057-4.

[18] Marek L, Hobbs M, McCarthy J, Wiki J, Tomintz M, Campbell M, et al. Investigating spatial variation and change (2006-2017) in childhood immunisation coverage in New Zealand. Social Science \& Medicine 2020; 264: 113292.

[19] Whitehead J, Scott N, Atatoa Carr P, Lawrenson R. Will access to COVID-19 vaccine in Aotearoa be equitable for priority populations? The New Zealand Medical Journal 2021; (forthcoming).

[20] Sharpe M. Covid-19 vaccines: DHB criticised Ministry of Health for rollout delays, warns of flourishing conspiracy theories. Stuff. 2021. https://www.stuff.co.nz/national/health/coronavirus/124684983/covid19-vaccinesdhb-criticised-ministry-of-health-for-rollout-delays-warns-of-flourishing-conspiracytheories (accessed 12 May 2021).

[21] Menon V, Thaker J. Aotearoa New Zealand Public Attitudes to COVID-19 Vaccine. Wellington, New Zealand: Massey University, 2020.

[22] Prickett K, Fletcher M, Chapple S, Doan N, Smith C. Life in lockdown: The economic and social effect of lockdown during Alert Level 4 in New Zealand. Victoria University of Wellington. 2020. http://researcharchive.vuw.ac.nz/handle/10063/9022 (accessed 12 May 2021).

[23] Opinions and Lifestyle Survey QMI - Office for National Statistics. Ons.gov.uk. 2021.

https://www.ons.gov.uk/peoplepopulationandcommunity/healthandsocialcare/healtha ndlifeexpectancies/methodologies/opinionsandlifestylesurveyqmi (accessed 12 May 2021).

[24] University of Essex, Institute for Social and Economic Research. Understanding Society: COVID-19 Study, 2020-2021 (4th edn). 2020. http://doi.org/10.5255/UKDA-SN-8644-3 (accessed 12 May 2021).

[25] Meredith S. Germany, France, Spain and Italy become latest countries to suspend AstraZeneca vaccine over blood clot fears. CNBC. 2021. https://www.cnbc.com/2021/03/15/covid-ireland-netherlands-suspend-astrazenecavaccine-amid-blood-clot-fears.html (accessed 12 May 2021).

[26] Ministry of Health NZ. National and DHB immunisation data. Wellington: Ministry of Health NZ, 2021.

[27] Nowlan, M., Willing, E., \& Turner, N. Influences and policies that affect immunisation coverage-a summary review of literature. The New Zealand Medical Journal 2019; 132: 1175-8716.

[28] Grant C, Chen M, Bandara D, Marks E, Gilchrist C, Lewycka S, et al. Antenatal immunisation intentions of expectant parents: Relationship to immunisation timeliness during infancy. Vaccine 2016; 34: 1379-1388. 
[29] Ellison-Loschmann L, Pearce N. Improving Access to Health Care Among New Zealand's Maori Population. American Journal of Public Health 2006; 96: 612-617.

[30] Rolleston A, Cassim S, Kidd J, Lawrenson R, Keenan R, Hokowhitu B. Seeing the unseen: evidence of kaupapa Māori health interventions. AlterNative: An International Journal of Indigenous Peoples 2020; 16: 129-136.

[31] Rolleston A, Doughty R, Poppe K. The effect of a 12-week exercise and lifestyle management programme on cardiac risk reduction: A pilot using a kaupapa Māori philosophy. International Journal of Indigenous Health 2017; 12: 116.

[32] Pitama S, Wells J, Faatoese A, Tikao-Mason K, Robertson P, Huria T, et al. A Kaupapa Māori approach to a community cohort study of heart disease in New Zealand. Australian and New Zealand Journal of Public Health 2011; 35: 249-255.

[33] Came H, O'Sullivan D, Kidd J, McCreanor T. The Waitangi Tribunal's WAI 2575 report: implications for decolonizing health systems. Health and Human Rights, 2020.

[34] Ministry of Justice. Waitangi Tribunal Report 2019. Wellington: New Zealand Ministry of Justice, 2019.

[35] Cram F. Mahi aroha: Māori work in times of trouble and disaster as an expression of a love for the people. Kōtuitui: New Zealand Journal of Social Sciences Online 2021; : $1-15$.

[36] Harris M, Williams D. Community checkpoints are an important and lawful part of NZ's Covid response. The Spinoff. 2020. https://thespinoff.co.nz/society/10-052020/community-checkpoints-an-important-and-lawful-part-of-nzs-covid-response/ (accessed 12 May 2021).

[37] Severinsen C, Ware F, Came H, Murray L. COVID-19 and Indigenous knowledge and leadership: (Re)centring public health curricula to address inequities. Australian and New Zealand Journal of Public Health 2021; 45: 6-8.

[38] Whaitiri D. Local Focus: Covid card experiment underway in Ngongotahā. NZ Herald. 2020. https://www.nzherald.co.nz/nz/local-focus-covid-card-experimentunderway-in-ngongotaha/XBL4CSMBIQCNMIJQKNGSD6IKBY/ (accessed 12 May 2021). 
TABLES AND FIGURES

Table 1. Likelihood of getting the COVID-19 vaccine $(n=1,284)$

\begin{tabular}{|c|c|c|c|c|c|c|}
\hline & $\begin{array}{c}\text { Total } \\
n\end{array}$ & $\begin{array}{c}\text { Very } \\
\text { unlikely } \\
\%\end{array}$ & $\begin{array}{c}\text { Somewhat } \\
\text { unlikely } \\
\%\end{array}$ & $\begin{array}{c}\text { Unsure } \\
\%\end{array}$ & $\begin{array}{c}\text { Somewhat } \\
\text { likely } \\
\%\end{array}$ & $\begin{array}{c}\text { Very } \\
\text { likely } \\
\%\end{array}$ \\
\hline Total & 1284 & 9.60 & 4.60 & 15.07 & 14.77 & 55.96 \\
\hline \multicolumn{7}{|l|}{ Age (years) } \\
\hline $18-34$ & 256 & 11.62 & 6.26 & 17.16 & 14.26 & 50.69 \\
\hline $35-64$ & 801 & 8.64 & 4.51 & 16.59 & 17.81 & 52.45 \\
\hline $65+$ & 223 & 9.59 & 2.52 & 7.95 & 7.06 & 72.87 \\
\hline \multicolumn{7}{|l|}{ Gender } \\
\hline Female & 550 & 8.20 & 4.08 & 17.71 & 14.52 & 55.49 \\
\hline Male & 734 & 11.10 & 5.15 & 12.24 & 15.04 & 56.47 \\
\hline \multicolumn{7}{|l|}{ Ethnicity (mutually inclusive) } \\
\hline NZ European & 798 & 8.62 & 4.51 & 15.08 & 12.36 & 59.43 \\
\hline Māori & 165 & 13.59 & 7.86 & 13.71 & 18.70 & 46.14 \\
\hline Pacific & 81 & 7.87 & 5.83 & 15.94 & 19.12 & 51.23 \\
\hline Asian & 134 & 10.31 & 2.04 & 18.25 & 25.52 & 43.88 \\
\hline Other & 106 & 11.75 & 1.34 & 12.77 & 12.80 & 61.35 \\
\hline \multicolumn{7}{|l|}{ Nativity } \\
\hline NZ born & 829 & 9.65 & 4.62 & 15.98 & 14.94 & 54.81 \\
\hline Not born in NZ & 293 & 8.67 & 2.63 & 16.46 & 11.89 & 60.36 \\
\hline \multicolumn{7}{|l|}{ Educational attainment } \\
\hline Primary/Secondary school & 336 & 12.65 & 2.90 & 18.27 & 14.61 & 51.57 \\
\hline Diploma & 425 & 12.05 & 6.41 & 15.21 & 12.11 & 54.23 \\
\hline Undergraduate/Postgraduate degree & 512 & 5.35 & 4.31 & 12.58 & 17.43 & 60.34 \\
\hline \multicolumn{7}{|l|}{ Annual household income (NZ\$) } \\
\hline$\$ 50,000$ or less & 360 & 9.80 & 4.63 & 15.79 & 13.19 & 56.59 \\
\hline$\$ 50,001-\$ 70,000$ & 186 & 12.74 & 7.99 & 16.67 & 10.95 & 51.65 \\
\hline$\$ 70,001-\$ 100,000$ & 240 & 7.34 & 4.21 & 15.37 & 17.35 & 55.73 \\
\hline$\$ 100,001-\$ 150,000$ & 236 & 6.63 & 4.75 & 14.01 & 21.01 & 53.61 \\
\hline More than $\$ 150,000$ & 167 & 8.21 & 2.94 & 8.05 & 10.62 & 70.18 \\
\hline \multicolumn{7}{|l|}{ Family structure } \\
\hline Two parents with dependent children & 401 & 12.61 & 3.24 & 16.96 & 20.06 & 47.13 \\
\hline Single parent & 64 & 19.29 & 9.54 & 19.92 & 11.55 & 39.71 \\
\hline Living alone & 130 & 9.59 & 7.79 & 11.56 & 13.10 & 57.96 \\
\hline Partner, no dependent children & 528 & 7.73 & 4.16 & 14.20 & 12.12 & 61.78 \\
\hline Other & 161 & 8.01 & 2.52 & 17.78 & 18.95 & 52.73 \\
\hline \multicolumn{7}{|l|}{ Work status } \\
\hline Employed & 881 & 9.00 & 4.72 & 16.06 & 15.92 & 54.29 \\
\hline Unemployed & 69 & 11.36 & 8.17 & 21.64 & 19.27 & 39.56 \\
\hline Not working & 334 & 10.63 & 3.61 & 11.54 & 11.29 & 62.93 \\
\hline \multicolumn{7}{|l|}{ Region } \\
\hline Auckland & 432 & 8.21 & 3.61 & 14.85 & 17.18 & 56.15 \\
\hline Bay of Plenty and Eastern North Island & 126 & 11.93 & 4.55 & 15.63 & 8.61 & 59.27 \\
\hline Canterbury and & & & & & & \\
\hline Marlborough/Nelson/Tasman & 220 & 4.77 & 6.78 & 14.99 & 17.05 & 56.41 \\
\hline Northland & 49 & 12.97 & 5.71 & 15.48 & 1.66 & 64.18 \\
\hline Southland & 83 & 20.13 & 4.71 & 12.38 & 13.29 & 49.49 \\
\hline Waikato and mid-North Island & 226 & 9.59 & 4.63 & 20.03 & 15.98 & 49.77 \\
\hline Wellington & 148 & 10.88 & 3.65 & 9.37 & 13.58 & 62.52 \\
\hline
\end{tabular}

Unweighted $n$ s, weighted \%s. Sum of subgroups may not total to 1,284 due to missing values. 
Table 2. Multinomial regression predicting likelihood of taking the COVID-19 vaccine $(n=1,284)$

\begin{tabular}{|c|c|c|c|c|c|c|}
\hline & \multicolumn{4}{|c|}{ Reference: Likely } & \multirow{2}{*}{\multicolumn{2}{|c|}{$\begin{array}{l}\text { Reference: Unlikely } \\
\text { vs. unsure }\end{array}$}} \\
\hline & \multicolumn{2}{|c|}{ vs. unlikely } & \multicolumn{2}{|c|}{ vs. unsure } & & \\
\hline & $\begin{array}{c}\text { RRR } \\
\text { (std. err.) }\end{array}$ & {$[95 \% \mathrm{CI}]$} & $\begin{array}{c}\text { RRR } \\
\text { (std. err.) }\end{array}$ & {$[95 \% \mathrm{CI}]$} & $\begin{array}{c}\text { RRR } \\
\text { (std. err.) }\end{array}$ & {$[95 \% \mathrm{CI}]$} \\
\hline \multicolumn{7}{|l|}{ Age (ref: $65+$ years) } \\
\hline 18-34 years & $\begin{array}{l}2.13^{*} \\
(0.74)\end{array}$ & $(1.08-4.22)$ & $\begin{array}{l}3.09 * * \\
(1.13)\end{array}$ & $(1.51-6.31)$ & $\begin{array}{c}1.45 \\
(0.67)\end{array}$ & $(0.58-3.60)$ \\
\hline $35-64$ years & $\begin{array}{c}1.29 \\
(0.39)\end{array}$ & $(0.72-2.33)$ & $\begin{array}{l}2.24^{*} \\
(0.74)\end{array}$ & $(1.17-4.27)$ & $\begin{array}{l}1.73 \\
(0.72)\end{array}$ & $(0.77-3.90)$ \\
\hline \multicolumn{7}{|l|}{ Gender (ref: male) } \\
\hline Female & $\begin{array}{c}0.75 \\
(0.14)\end{array}$ & $(0.52-1.07)$ & $\begin{array}{l}1.58^{* *} \\
(0.27)\end{array}$ & $(1.14-2.21)$ & $\begin{array}{c}2.12^{* * * *} \\
(0.48)\end{array}$ & $(1.36-3.32)$ \\
\hline \multicolumn{7}{|l|}{ Ethnicity (ref: NZ European/Pākehā) } \\
\hline Māori & $\begin{array}{l}1.56+ \\
(0.38)\end{array}$ & $(0.97-2.50)$ & $\begin{array}{c}1.09 \\
(0.27)\end{array}$ & $(0.67-1.78)$ & $\begin{array}{c}0.70 \\
(0.22)\end{array}$ & $(0.38-1.28)$ \\
\hline Pacific & $\begin{array}{l}1.08 \\
(0.42)\end{array}$ & $(0.51-2.29)$ & $\begin{array}{c}1.22 \\
(0.39)\end{array}$ & $(0.65-2.30)$ & $\begin{array}{c}1.13 \\
(0.51)\end{array}$ & $(0.47-2.75)$ \\
\hline Asian & $\begin{array}{l}1.18 \\
(0.42)\end{array}$ & $(0.59-2.35)$ & $\begin{array}{c}1.51 \\
(0.44)\end{array}$ & $(0.85-2.68)$ & $\begin{array}{c}1.28 \\
(0.53)\end{array}$ & $(0.57-2.89)$ \\
\hline Other & $\begin{array}{l}1.07 \\
(0.39)\end{array}$ & $(0.53-2.17)$ & $\begin{array}{c}0.86 \\
(0.31)\end{array}$ & $(0.42-1.74)$ & $\begin{array}{c}0.80 \\
(0.37)\end{array}$ & $(0.32-2.00)$ \\
\hline \multicolumn{7}{|l|}{ Nativity (ref: NZ born) } \\
\hline Not born in NZ & $\begin{array}{c}0.98 \\
(0.25)\end{array}$ & $(0.60-1.63)$ & $\begin{array}{c}0.98 \\
(0.23)\end{array}$ & $(0.63-1.54)$ & $\begin{array}{c}1.00 \\
(0.31)\end{array}$ & $(0.54-1.83)$ \\
\hline \multicolumn{7}{|l|}{$\begin{array}{l}\text { Educational attainment } \\
\text { (ref: undergraduate/postgraduate } \\
\text { degree) }\end{array}$} \\
\hline Primary/Secondary school & $\begin{array}{l}1.82 * \\
(0.46)\end{array}$ & $(1.11-2.99)$ & $\begin{array}{l}1.70^{*} \\
(0.39)\end{array}$ & $(1.09-2.66)$ & $\begin{array}{c}0.93 \\
(0.29)\end{array}$ & $(0.51-1.72)$ \\
\hline Diploma & $\begin{array}{c}2.47 * * * \\
(0.56)\end{array}$ & $(1.59-3.84)$ & $\begin{array}{l}1.52 * \\
(0.32)\end{array}$ & $(1.01-2.30)$ & $\begin{array}{l}0.62+ \\
(0.17)\end{array}$ & $(0.36-1.07)$ \\
\hline \multicolumn{7}{|l|}{$\begin{array}{l}\text { Annual household income (ref: More } \\
\text { than } \$ 150,000 \text { ) }\end{array}$} \\
\hline$\$ 50,000$ or less & $\begin{array}{c}1.46 \\
(0.53)\end{array}$ & $(0.72-2.96)$ & $\begin{array}{l}2.09 * \\
(0.73)\end{array}$ & $(1.05-4.15)$ & $\begin{array}{c}1.43 \\
(0.66)\end{array}$ & $(0.58-3.55)$ \\
\hline$\$ 50,001-\$ 70,000$ & $\begin{array}{l}1.58 \\
(0.55)\end{array}$ & $(0.80-3.12)$ & $\begin{array}{l}1.82+ \\
(0.64)\end{array}$ & $(0.92-3.62)$ & $\begin{array}{l}1.16 \\
(0.52)\end{array}$ & $(0.48-2.81)$ \\
\hline$\$ 70,001-\$ 100,000$ & $\begin{array}{c}0.95 \\
(0.33)\end{array}$ & $(0.48-1.89)$ & $\begin{array}{l}1.96^{*} \\
(0.63)\end{array}$ & $(1.05-3.68)$ & $\begin{array}{l}2.07+ \\
(0.90)\end{array}$ & $(0.88-4.87)$ \\
\hline$\$ 100,001-\$ 150,000$ & $\begin{array}{c}0.94 \\
(0.33)\end{array}$ & $(0.47-1.85)$ & $\begin{array}{l}1.33 \\
(0.43)\end{array}$ & $(0.70-2.53)$ & $\begin{array}{c}1.42 \\
(0.63)\end{array}$ & $(0.60-3.38)$ \\
\hline \multicolumn{7}{|l|}{$\begin{array}{l}\text { Family structure (ref: Two parents, } \\
\text { dependent children) }\end{array}$} \\
\hline Single parent & $\begin{array}{l}1.57 \\
(0.56)\end{array}$ & $(0.78-3.17)$ & $\begin{array}{c}0.94 \\
(0.36)\end{array}$ & $(0.44-2.01)$ & $\begin{array}{c}0.59 \\
(0.27)\end{array}$ & $(0.24-1.44)$ \\
\hline Living alone & $\begin{array}{c}0.81 \\
(0.25)\end{array}$ & $(0.44-1.49)$ & $\begin{array}{l}0.39 * \\
(0.15)\end{array}$ & $(0.19-0.81)$ & $\begin{array}{c}0.49 \\
(0.21)\end{array}$ & $(0.20-1.15)$ \\
\hline Partner, no dependent children & $\begin{array}{l}0.61 * \\
(0.14)\end{array}$ & $(0.40-0.95)$ & $\begin{array}{c}0.86 \\
(0.17)\end{array}$ & $(0.58-1.27)$ & $\begin{array}{c}1.40 \\
(0.38)\end{array}$ & $(0.82-2.39)$ \\
\hline Other & $\begin{array}{l}0.47 * \\
(0.15)\end{array}$ & $(0.25-0.89)$ & $\begin{array}{c}0.72 \\
(0.20)\end{array}$ & $(0.42-1.24)$ & $\begin{array}{c}1.54 \\
(0.60)\end{array}$ & $(0.72-3.32)$ \\
\hline
\end{tabular}

Table 2 continued on next page 
Table 2 continued

\begin{tabular}{lcccccc}
\hline Work status (ref: employed) & & & & & & \\
$\quad$ Unemployed & 1.09 & $(0.52-2.27)$ & 0.75 & $(0.35-1.59)$ & 0.69 & $(0.27-1.76)$ \\
& $(0.41)$ & & $(0.29)$ & & $(0.33)$ & \\
Not working & 1.14 & $(0.68-1.93)$ & 0.70 & $(0.43-1.15)$ & 0.61 & $(0.32-1.18)$ \\
& $(0.30)$ & & $(0.18)$ & & $(0.20)$ & \\
Region (ref: Auckland) & & & & & & \\
$\quad$ Bay of Plenty and Eastern North & 1.16 & $(0.63-2.11)$ & 1.13 & $(0.63-2.01)$ & 0.98 & $(0.46-2.07)$ \\
Island & $(0.36)$ & & $(0.33)$ & & $(0.37)$ & \\
Canterbury and & 0.85 & $(0.49-1.45)$ & 0.92 & $(0.57-1.49)$ & 1.09 & $(0.56-2.10)$ \\
Marlborough/Nelson/Tasman & $(0.23)$ & & $(0.22)$ & & $(0.37)$ & \\
Northland & 1.60 & $(0.71-3.63)$ & 1.01 & $(0.41-2.49)$ & 0.63 & $(0.21-1.87)$ \\
& $(0.67)$ & & $(0.46)$ & & $(0.35)$ & \\
Southland & $1.89+$ & $(1.00-3.57)$ & 0.58 & $(0.26-1.27)$ & $0.31 *$ & $(0.12-0.77)$ \\
& $(0.61)$ & & $(0.23)$ & & $(0.14)$ & \\
Waikato and mid-North Island & 1.08 & $(0.65-1.81)$ & 1.15 & $(0.72-1.84)$ & 1.06 & $(0.57-1.99)$ \\
& $(0.28)$ & & $(0.28)$ & & $(0.34)$ & \\
Wellington & 0.68 & $(0.35-1.30)$ & 0.68 & $(0.38-1.23)$ & 1.00 & $(0.44-2.28)$ \\
& $(0.23)$ & & $(0.21)$ & & $(0.42)$ & \\
Constant & $0.09^{* * *}$ & $(0.04-0.22)$ & $0.05 * * *$ & $(0.02-0.12)$ & 0.54 & $(0.16-1.80)$ \\
& $(0.04)$ & & $(0.02)$ & & $(0.33)$ & \\
Pseudo R & .06 & & .06 & & .06 & \\
$n$ & 1,284 & & 1,284 & & 1,284 & \\
\hline
\end{tabular}

*** $\mathrm{p}<0.001, * * \mathrm{p}<0.01,{ }^{*} \mathrm{p}<0.05,+\mathrm{p}<0.10 . \mathrm{CI}=$ Confidence intervals. $\mathrm{RRR}=$ Relative risk ratio. 
Figure 1. Reasons why unlikely or unsure of getting the COVID-19 vaccine $(n=375)$

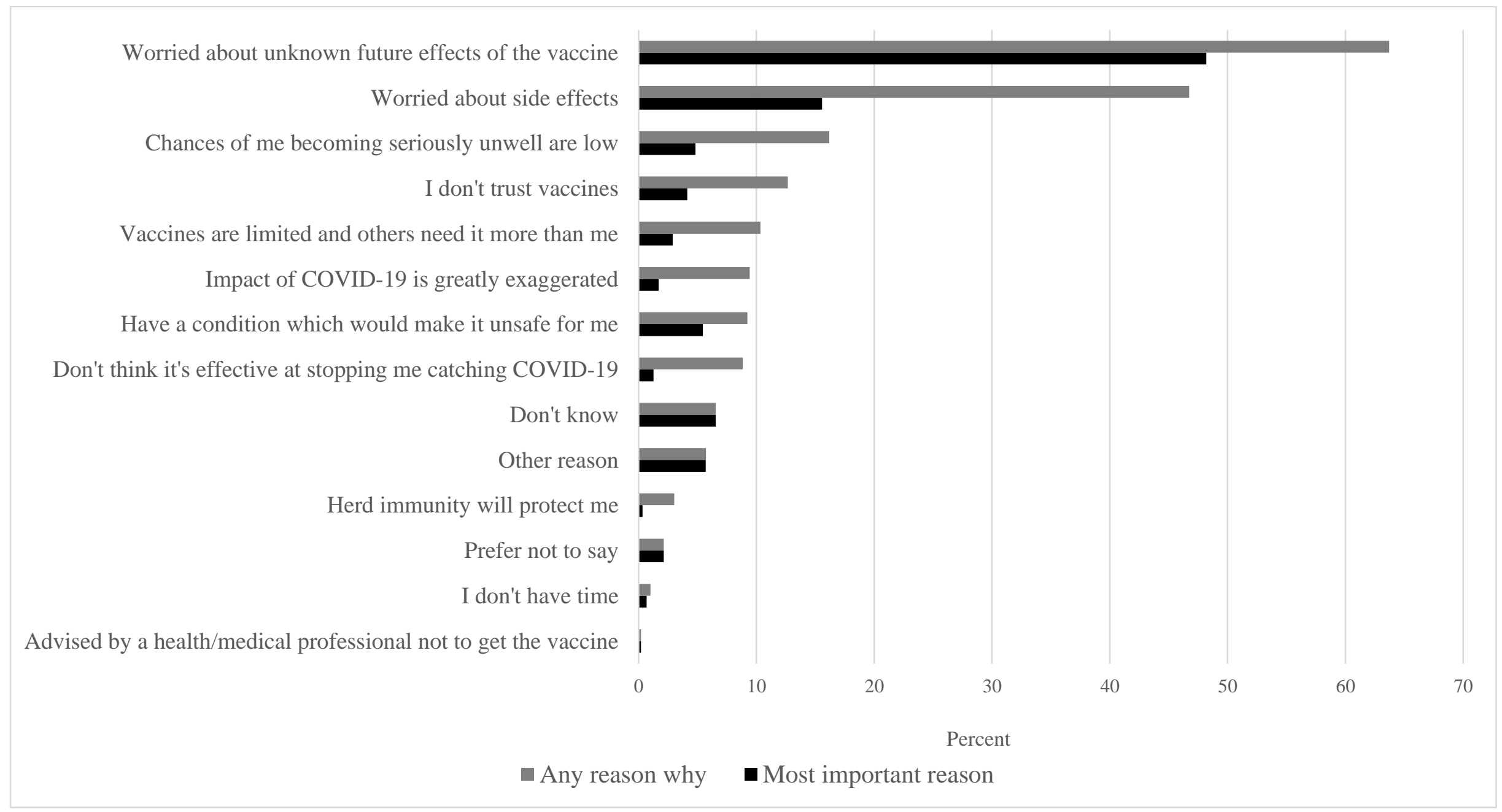

Note. Weighted $\%$ s. 
Figure 2. Odds likelihood of reporting reason for women compared to men $(n=375)$

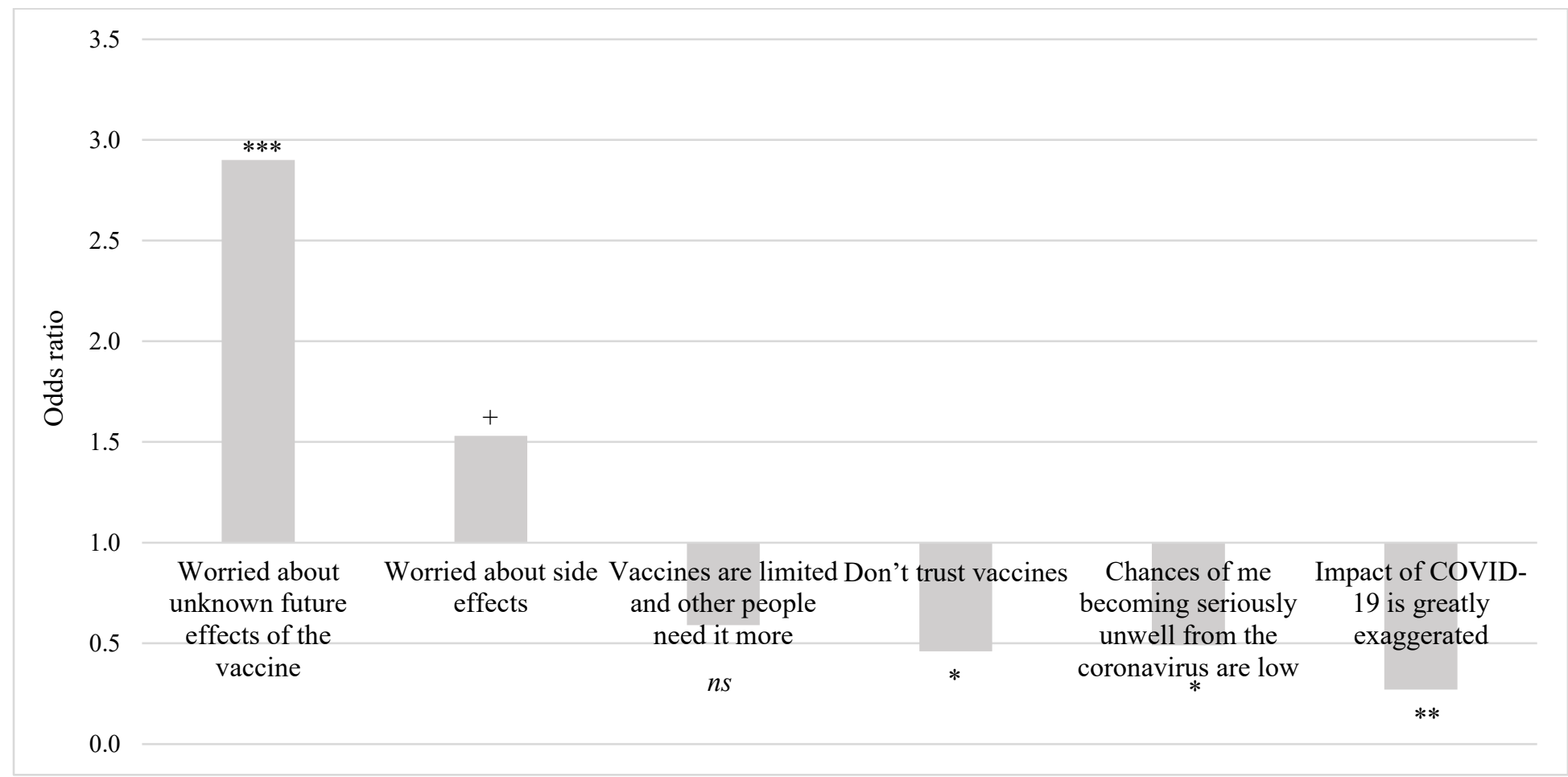

Note. $* * * \mathrm{p}<0.001, * * \mathrm{p}<0.01, * \mathrm{p}<0.05,+\mathrm{p}<0.10, n s$ not statistically different from men. Models control for: age, ethnicity, nativity, educational attainment, household income, household structure, work status, and region of residence. Full model results presented in Table A2 in the appendix. 
Figure 3. Reasons likely to take the COVID-19 vaccine $(n=909)$

To stop me catching COVID-19 or getting very ill from it

Protect other people from catching COVID-19

Help my community to get back to normal

Vaccine won`t work unless most people in NZ get it

Help my social and family life to get back to normal

I take the vaccines offered or recommended to me

I am a key worker working with high risk groups

Don’t know

Prefer not to say |

0

10

20

30

40

Percent

- Any reason why

- Most important reason

Note. Weighted \%s. 


\section{APPENDIX}

Table A1. Reasons why unlikely to or unsure of getting the vaccine $(n=375)$

\begin{tabular}{lrr}
\hline & $n$ & $\%$ \\
\hline All reasons why not & 235 & 63.73 \\
I am worried about unknown future effects of the vaccine & 184 & 46.74 \\
I am worried about side effects & 41 & 10.34 \\
Vaccines are limited and other people need it more than me & 50 & 12.67 \\
I don't trust vaccines & 60 & 16.18 \\
The chances of me becoming seriously unwell from the coronavirus are low & 39 & 9.42 \\
The impact of the coronavirus is being greatly exaggerated & 35 & 8.85 \\
I don't think it would be effective at stopping me catching the coronavirus & 31 & 9.23 \\
I have a condition which would make it unsafe for me & 15 & 3.02 \\
Herd immunity will protect me even if I don't have the vaccine & 5 & 1.00 \\
I don't have time & 1 & 0.21 \\
I have been advised by a health or medical professional not to get the vaccine & 25 & 5.72 \\
Other (please specify) & 28 & 6.55 \\
Don't know & 8 & 2.13 \\
Prefer not to say & & \\
Number of reasons cited & 36 & 8.68 \\
Gave no reason & 139 & 40.1 \\
1 reason & 94 & 24.81 \\
2 reasons & 57 & 14.57 \\
3 reasons & 49 & 11.84 \\
4 or more reasons & & \\
Most important reason & 171 & 48.19 \\
I am worried about unknown future effects of the vaccine & 60 & 15.57 \\
I am worried about side effects & 11 & 2.90 \\
Vaccines are limited and other people need it more than me & 16 & 4.14 \\
I don't trust vaccines & 15 & 4.83 \\
The chances of me becoming seriously unwell from the coronavirus are low & 7 & 1.69 \\
The impact of the coronavirus is being greatly exaggerated & 6 & 1.27 \\
I don't think it would be effective at stopping me catching the coronavirus & 19 & 5.45 \\
I have a condition which would make it unsafe for me & 2 & 0.34 \\
Herd immunity will protect me even if I don't have the vaccine & 4 & 0.67 \\
I don't have time & 1 & 0.21 \\
I have been advised by a health or medical professional not to get the vaccine & 24 & 5.70 \\
Other (please specify) & 28 & 6.55 \\
Don't know & 8 & 2.13 \\
Prefer not to say & \\
\hline Unweigh & & \\
& & \\
& &
\end{tabular}

Unweighted ns, weighted \%s. 


\begin{tabular}{|c|c|c|c|c|c|c|c|c|c|c|c|c|}
\hline & \multicolumn{2}{|c|}{$\begin{array}{l}\text { Worried about } \\
\text { unknown future effects } \\
\text { of the vaccine } \\
\text { Model } 1\end{array}$} & \multicolumn{2}{|c|}{$\begin{array}{l}\text { Worried about side } \\
\text { effects } \\
\text { Model } 2\end{array}$} & \multicolumn{2}{|c|}{$\begin{array}{l}\text { Vaccines are limited and } \\
\text { other people need it } \\
\text { more than me } \\
\text { Model } 3\end{array}$} & \multicolumn{2}{|c|}{$\begin{array}{c}\text { I don't trust vaccines } \\
\text { Model } 4\end{array}$} & \multicolumn{2}{|c|}{$\begin{array}{c}\text { Chances of me } \\
\text { becoming seriously } \\
\text { unwell from the } \\
\text { coronavirus are low } \\
\text { Model } 5\end{array}$} & \multicolumn{2}{|c|}{$\begin{array}{l}\text { Impact of the } \\
\text { coronavirus is being } \\
\text { greatly exaggerated } \\
\text { Model } 6\end{array}$} \\
\hline & OR & {$[95 \% \mathrm{CI}]$} & OR & {$[95 \% \mathrm{CI}]$} & OR & {$[95 \% \mathrm{CI}]$} & OR & {$[95 \% \mathrm{CI}]$} & OR & {$[95 \% \mathrm{CI}]$} & OR & {$[95 \% \mathrm{CI}]$} \\
\hline \multicolumn{13}{|l|}{ Age (ref: $65+$ years) } \\
\hline 18-34 years & $\begin{array}{l}2.75^{*} \\
(1.36)\end{array}$ & $(1.05-7.25)$ & $\begin{array}{c}0.64 \\
(0.30)\end{array}$ & $(0.25-1.61)$ & $\begin{array}{c}0.69 \\
(0.51)\end{array}$ & $(0.16-2.96)$ & $\begin{array}{c}0.70 \\
(0.47)\end{array}$ & $(0.19-2.62)$ & $\begin{array}{c}1.02 \\
(0.62)\end{array}$ & $(0.31-3.33)$ & $\begin{array}{c}0.36 \\
(0.26)\end{array}$ & $(0.09-1.47)$ \\
\hline $35-64$ years & $\begin{array}{l}3.01 * \\
(1.33)\end{array}$ & $(1.26-7.18)$ & $\begin{array}{c}0.59 \\
(0.25)\end{array}$ & $(0.25-1.36)$ & $\begin{array}{c}0.89 \\
(0.58)\end{array}$ & $(0.24-3.23)$ & $\begin{array}{c}0.70 \\
(0.42)\end{array}$ & $(0.21-2.29)$ & $\begin{array}{c}0.49 \\
(0.27)\end{array}$ & $(0.16-1.45)$ & $\begin{array}{l}0.32+ \\
(0.21)\end{array}$ & $(0.09-1.13)$ \\
\hline \multicolumn{13}{|l|}{ Gender (ref: male) } \\
\hline Female & $\begin{array}{c}2.90 * * * \\
(0.77)\end{array}$ & $(1.72-4.87)$ & $\begin{array}{l}1.53+ \\
(0.37)\end{array}$ & $(0.94-2.47)$ & $\begin{array}{c}0.59 \\
(0.23)\end{array}$ & $(0.27-1.28)$ & $\begin{array}{l}0.46^{*} \\
(0.17)\end{array}$ & $(0.22-0.94)$ & $\begin{array}{l}0.49^{*} \\
(0.17)\end{array}$ & $(0.24-0.97)$ & $\begin{array}{l}0.27 * * \\
(0.12)\end{array}$ & $(0.11-0.62)$ \\
\hline \multicolumn{13}{|l|}{$\begin{array}{l}\text { Ethnicity (ref: NZ } \\
\text { European/Pākehā) }\end{array}$} \\
\hline Māori & $\begin{array}{l}0.47 * \\
(0.16)\end{array}$ & $(0.24-0.93)$ & $\begin{array}{c}0.81 \\
(0.26)\end{array}$ & $(0.43-1.53)$ & $\begin{array}{c}0.67 \\
(0.38)\end{array}$ & $(0.22-2.04)$ & $\begin{array}{c}1.29 \\
(0.65)\end{array}$ & $(0.48-3.45)$ & $\begin{array}{c}0.66 \\
(0.32)\end{array}$ & $(0.26-1.69)$ & $\begin{array}{c}0.78 \\
(0.43)\end{array}$ & $(0.26-2.29)$ \\
\hline Pacific & $\begin{array}{l}1.18 \\
(0.57)\end{array}$ & $(0.45-3.05)$ & $\begin{array}{c}1.74 \\
(0.80)\end{array}$ & $(0.70-4.31)$ & $\begin{array}{c}1.01 \\
(0.72)\end{array}$ & $(0.25-4.06)$ & $\begin{array}{c}0.94 \\
(0.56)\end{array}$ & $(0.29-3.00)$ & $\begin{array}{c}0.57 \\
(0.42)\end{array}$ & $(0.14-2.37)$ & $\mathrm{n} / \mathrm{a}$ & \\
\hline Asian & $\begin{array}{c}0.50 \\
(0.26)\end{array}$ & $(0.18-1.36)$ & $\begin{array}{c}0.52 \\
(0.25)\end{array}$ & $(0.20-1.36)$ & $\begin{array}{c}1.34 \\
(1.00)\end{array}$ & $(0.31-5.81)$ & $\begin{array}{c}1.06 \\
(0.71)\end{array}$ & $(0.28-3.94)$ & $\begin{array}{c}2.18 \\
(1.37)\end{array}$ & $(0.63-7.48)$ & $\begin{array}{l}0.23+ \\
(0.20)\end{array}$ & $(0.04-1.29)$ \\
\hline Other & $\begin{array}{l}0.31 * \\
(0.16)\end{array}$ & $(0.11-0.87)$ & $\begin{array}{l}0.36+ \\
(0.19)\end{array}$ & $(0.13-1.02)$ & $\begin{array}{c}0.90 \\
(0.69)\end{array}$ & $(0.20-4.00)$ & $\begin{array}{c}1.00 \\
(0.69)\end{array}$ & $(0.26-3.88)$ & $\begin{array}{c}1.72 \\
(1.14)\end{array}$ & $(0.47-6.29)$ & $\begin{array}{l}0.17 * \\
(0.15)\end{array}$ & $(0.03-0.97)$ \\
\hline Nativity (ref: NZ born) & & & & & & & & & & & & \\
\hline Not born in NZ & $\begin{array}{l}0.47+ \\
(0.19)\end{array}$ & $(0.22-1.03)$ & $\begin{array}{c}0.63 \\
(0.23)\end{array}$ & $(0.31-1.29)$ & $\begin{array}{c}1.75 \\
(1.04)\end{array}$ & $(0.55-5.60)$ & $\begin{array}{c}0.55 \\
(0.27)\end{array}$ & $(0.21-1.44)$ & $\begin{array}{c}4.65^{* *} \\
(2.65)\end{array}$ & $(1.52-14.21)$ & $\begin{array}{c}0.74 \\
(0.46)\end{array}$ & $(0.22-2.48)$ \\
\hline $\begin{array}{l}\text { Educational attainment } \\
\text { (ref: undergraduate/ } \\
\text { postgraduate degree) } \\
\text { Primary/Secondary }\end{array}$ & & & & & & & & & & & & \\
\hline school & $\begin{array}{c}0.81 \\
(0.27)\end{array}$ & $(0.42-1.56)$ & $\begin{array}{l}0.54+ \\
(0.18)\end{array}$ & $(0.29-1.02)$ & $\begin{array}{l}0.45+ \\
(0.22)\end{array}$ & $(0.17-1.16)$ & $\begin{array}{r}1.18 \\
(0.59)\end{array}$ & $(0.44-3.13)$ & $\begin{array}{c}0.74 \\
(0.31)\end{array}$ & $(0.33-1.66)$ & $\begin{array}{c}1.04 \\
(0.55)\end{array}$ & $(0.36-2.95)$ \\
\hline
\end{tabular}

Table A2 continued on next page 
Table A2 continued

\begin{tabular}{|c|c|c|c|c|c|c|c|c|c|c|c|c|}
\hline Diploma & $\begin{array}{c}0.95 \\
(0.30)\end{array}$ & $(0.52-1.76)$ & $\begin{array}{c}1.02 \\
(0.30)\end{array}$ & $(0.58-1.80)$ & $\begin{array}{l}0.34 * \\
(0.16)\end{array}$ & $(0.14-0.84)$ & $\begin{array}{c}1.96 \\
(0.82)\end{array}$ & $(0.86-4.46)$ & $\begin{array}{l}0.50+ \\
(0.20)\end{array}$ & $(0.23-1.08)$ & $\begin{array}{c}1.07 \\
(0.50)\end{array}$ & $(0.43-2.69)$ \\
\hline \multicolumn{13}{|l|}{$\begin{array}{l}\text { Annual household } \\
\text { income (ref: More than } \\
\$ 150,000)\end{array}$} \\
\hline$\$ 50,000$ or less & $\begin{array}{c}0.84 \\
(0.42)\end{array}$ & $(0.32-2.22)$ & $\begin{array}{c}1.15 \\
(0.54)\end{array}$ & $(0.45-2.91)$ & $\begin{array}{c}1.01 \\
(0.74)\end{array}$ & $(0.24-4.25)$ & $\begin{array}{l}5.03+ \\
(4.29)\end{array}$ & $(0.94-26.74)$ & $\begin{array}{c}1.90 \\
(1.47)\end{array}$ & $(0.42-8.67)$ & $\begin{array}{c}1.23 \\
(1.03)\end{array}$ & $(0.24-6.35)$ \\
\hline$\$ 50,001-\$ 70,000$ & $\begin{array}{c}1.22 \\
(0.62)\end{array}$ & $(0.46-3.28)$ & $\begin{array}{c}1.60 \\
(0.77)\end{array}$ & $(0.62-4.12)$ & $\begin{array}{c}0.84 \\
(0.65)\end{array}$ & $(0.18-3.85)$ & $\begin{array}{l}4.47+ \\
(3.80)\end{array}$ & $(0.85-23.62)$ & $\begin{array}{c}2.23 \\
(1.73)\end{array}$ & $(0.49-10.16)$ & $\begin{array}{c}0.79 \\
(0.68)\end{array}$ & $(0.15-4.27)$ \\
\hline$\$ 70,001-\$ 100,000$ & $\begin{array}{c}2.19 \\
(1.10)\end{array}$ & $(0.82-5.84)$ & $\begin{array}{c}1.76 \\
(0.82)\end{array}$ & $(0.71-4.38)$ & $\begin{array}{c}1.45 \\
(1.04)\end{array}$ & $(0.36-5.90)$ & $\begin{array}{c}2.28 \\
(1.94)\end{array}$ & $(0.43-12.07)$ & $\begin{array}{c}1.66 \\
(1.28)\end{array}$ & $(0.37-7.50)$ & $\begin{array}{c}0.58 \\
(0.50)\end{array}$ & $(0.11-3.18)$ \\
\hline$\$ 100,001-\$ 150,000$ & $\begin{array}{c}1.01 \\
(0.49)\end{array}$ & $(0.39-2.61)$ & $\begin{array}{c}0.89 \\
(0.41)\end{array}$ & $(0.35-2.21)$ & $\begin{array}{c}1.30 \\
(0.94)\end{array}$ & $(0.31-5.37)$ & $\begin{array}{l}3.97+ \\
(3.29)\end{array}$ & $(0.78-20.11)$ & $\begin{array}{c}1.84 \\
(1.43)\end{array}$ & $(0.40-8.40)$ & $\begin{array}{c}1.66 \\
(1.32)\end{array}$ & $(0.35-7.86)$ \\
\hline \multicolumn{13}{|l|}{$\begin{array}{l}\text { Family structure (ref: } \\
\text { Two parents, dependent } \\
\text { children) }\end{array}$} \\
\hline Single parent & $\begin{array}{c}1.11 \\
(0.58)\end{array}$ & $(0.40-3.08)$ & $\begin{array}{c}0.51 \\
(0.24)\end{array}$ & $(0.20-1.29)$ & $\begin{array}{l}1.10 \\
(0.94)\end{array}$ & $(0.21-5.85)$ & $\begin{array}{l}1.10 \\
(0.67)\end{array}$ & $(0.33-3.66)$ & $\begin{array}{c}0.72 \\
(0.47)\end{array}$ & $(0.20-2.61)$ & $\begin{array}{c}0.74 \\
(0.56)\end{array}$ & $(0.17-3.24)$ \\
\hline Living alone & $\begin{array}{c}0.80 \\
(0.37)\end{array}$ & $(0.32-2.00)$ & $\begin{array}{l}0.34 * \\
(0.15)\end{array}$ & $(0.14-0.83)$ & $\begin{array}{c}1.85 \\
(1.21)\end{array}$ & $(0.51-6.66)$ & $\begin{array}{c}0.26 \\
(0.22)\end{array}$ & $(0.05-1.34)$ & $\begin{array}{l}0.22 * \\
(0.16)\end{array}$ & $(0.05-0.92)$ & $\begin{array}{c}0.36 \\
(0.27)\end{array}$ & $(0.08-1.55)$ \\
\hline $\begin{array}{l}\text { Partner, no dependent } \\
\text { children }\end{array}$ & $\begin{array}{c}1.09 \\
(0.34)\end{array}$ & $(0.59-2.00)$ & $\begin{array}{c}0.85 \\
(0.24)\end{array}$ & $(0.49-1.50)$ & $\begin{array}{c}1.94 \\
(0.88)\end{array}$ & $(0.79-4.74)$ & $\begin{array}{c}0.70 \\
(0.30)\end{array}$ & $(0.31-1.61)$ & $\begin{array}{c}0.53 \\
(0.21)\end{array}$ & $(0.24-1.16)$ & $\begin{array}{l}0.22 * * \\
(0.12)\end{array}$ & $(0.08-0.65)$ \\
\hline Other & $\begin{array}{c}0.53 \\
(0.22)\end{array}$ & $(0.23-1.19)$ & $\begin{array}{c}0.83 \\
(0.33)\end{array}$ & $(0.38-1.81)$ & $\begin{array}{c}1.02 \\
(0.74)\end{array}$ & $(0.24-4.25)$ & $\begin{array}{c}0.94 \\
(0.53)\end{array}$ & $(0.31-2.85)$ & $\begin{array}{c}0.45 \\
(0.24)\end{array}$ & $(0.15-1.30)$ & $\begin{array}{c}1.07 \\
(0.66)\end{array}$ & $(0.32-3.57)$ \\
\hline \multicolumn{13}{|l|}{$\begin{array}{l}\text { Work status (ref: } \\
\text { employed) }\end{array}$} \\
\hline Unemployed & $\begin{array}{c}2.48 \\
(1.47)\end{array}$ & $(0.77-7.92)$ & $\begin{array}{c}1.59 \\
(0.81)\end{array}$ & $(0.58-4.32)$ & $\begin{array}{c}0.87 \\
(0.72)\end{array}$ & $(0.17-4.39)$ & $\begin{array}{c}0.77 \\
(0.56)\end{array}$ & $(0.19-3.22)$ & $\begin{array}{c}0.91 \\
(0.67)\end{array}$ & $(0.22-3.81)$ & $\begin{array}{c}1.77 \\
(1.33)\end{array}$ & $(0.41-7.72)$ \\
\hline Not working & $\begin{array}{c}1.17 \\
(0.41)\end{array}$ & $(0.58-2.34)$ & $\begin{array}{c}0.62 \\
(0.21)\end{array}$ & $(0.32-1.20)$ & $\begin{array}{c}0.58 \\
(0.35)\end{array}$ & $(0.18-1.89)$ & $\begin{array}{c}0.77 \\
(0.39)\end{array}$ & $(0.29-2.06)$ & $\begin{array}{l}1.05 \\
(0.47)\end{array}$ & $(0.44-2.52)$ & $\begin{array}{c}1.37 \\
(0.77)\end{array}$ & $(0.46-4.10)$ \\
\hline
\end{tabular}

Table A2 continued on next page 


\begin{tabular}{|c|c|c|c|c|c|c|c|c|c|c|c|c|}
\hline \multicolumn{13}{|l|}{ Region (ref: Auckland) } \\
\hline $\begin{array}{c}\text { Bay of Plenty and } \\
\text { Eastern North Island }\end{array}$ & $\begin{array}{c}1.38 \\
(0.60)\end{array}$ & $(0.58-3.25)$ & $\begin{array}{c}1.43 \\
(0.59)\end{array}$ & $(0.63-3.23)$ & $\begin{array}{c}0.62 \\
(0.52)\end{array}$ & $(0.12-3.24)$ & $\begin{array}{c}1.13 \\
(0.61)\end{array}$ & $(0.40-3.24)$ & $\begin{array}{c}0.86 \\
(0.52)\end{array}$ & $(0.26-2.80)$ & $\begin{array}{c}2.47 \\
(1.57)\end{array}$ & $(0.71-8.60)$ \\
\hline $\begin{array}{l}\text { Canterbury and } \\
\text { Marlborough/Nelson/Tas } \\
\text { man }\end{array}$ & $\begin{array}{c}1.15 \\
(0.44)\end{array}$ & $(0.55-2.41)$ & $\begin{array}{c}0.97 \\
(0.35)\end{array}$ & $(0.48-1.97)$ & $\begin{array}{c}1.74 \\
(1.01)\end{array}$ & $(0.56-5.41)$ & $\begin{array}{c}0.67 \\
(0.37)\end{array}$ & $(0.23-2.00)$ & $\begin{array}{c}1.07 \\
(0.54)\end{array}$ & $(0.40-2.85)$ & $\begin{array}{c}1.00 \\
(0.65)\end{array}$ & $(0.28-3.60)$ \\
\hline Northland & $\begin{array}{c}2.14 \\
(1.39)\end{array}$ & $(0.60-7.65)$ & $\begin{array}{c}1.08 \\
(0.63)\end{array}$ & $(0.34-3.38)$ & $\begin{array}{l}4.47^{*} \\
(3.38)\end{array}$ & $(1.02-19.64)$ & $\begin{array}{c}1.02 \\
(0.89)\end{array}$ & $(0.18-5.65)$ & $\begin{array}{c}1.44 \\
(1.10)\end{array}$ & $(0.32-6.42)$ & $\begin{array}{l}4.09+ \\
(3.48)\end{array}$ & $(0.77-21.71)$ \\
\hline Southland & $\begin{array}{c}1.85 \\
(0.98)\end{array}$ & $(0.66-5.22)$ & $\begin{array}{c}0.57 \\
(0.27)\end{array}$ & $(0.22-1.45)$ & $\begin{array}{c}1.67 \\
(1.29)\end{array}$ & $(0.37-7.57)$ & $\begin{array}{c}0.37 \\
(0.31)\end{array}$ & $(0.07-1.90)$ & $\begin{array}{l}2.59+ \\
(1.45)\end{array}$ & $(0.86-7.75)$ & $\begin{array}{c}1.73 \\
(1.28)\end{array}$ & $(0.41-7.39)$ \\
\hline $\begin{array}{l}\text { Waikato and mid- } \\
\text { North Island }\end{array}$ & $\begin{array}{l}2.27 * \\
(0.86)\end{array}$ & $(1.08-4.76)$ & $\begin{array}{c}1.34 \\
(0.46)\end{array}$ & $(0.68-2.63)$ & $\begin{array}{c}1.98 \\
(1.08)\end{array}$ & $(0.68-5.77)$ & $\begin{array}{c}0.59 \\
(0.30)\end{array}$ & $(0.22-1.61)$ & $\begin{array}{c}1.29 \\
(0.59)\end{array}$ & $(0.52-3.15)$ & $\begin{array}{c}1.41 \\
(0.84)\end{array}$ & $(0.44-4.51)$ \\
\hline Wellington & $\begin{array}{c}1.20 \\
(0.55)\end{array}$ & $(0.49-2.95)$ & $\begin{array}{c}0.75 \\
(0.33)\end{array}$ & $(0.31-1.80)$ & $\begin{array}{c}1.79 \\
(1.19)\end{array}$ & $(0.48-6.58)$ & $\begin{array}{c}0.78 \\
(0.50)\end{array}$ & $(0.22-2.75)$ & $\begin{array}{c}0.87 \\
(0.56)\end{array}$ & $(0.25-3.06)$ & $\begin{array}{c}1.10 \\
(0.86)\end{array}$ & $(0.24-5.06)$ \\
\hline Constant & $\begin{array}{c}0.63 \\
(0.44)\end{array}$ & $(0.16-2.48)$ & $\begin{array}{c}2.39 \\
(1.60)\end{array}$ & $(0.64-8.89)$ & $\begin{array}{l}0.10^{*} \\
(0.11)\end{array}$ & $(0.01-0.85)$ & $\begin{array}{l}0.14+ \\
(0.15)\end{array}$ & $(0.02-1.15)$ & $\begin{array}{l}0.12 * \\
(0.12)\end{array}$ & $(0.02-0.90)$ & $\begin{array}{c}0.89 \\
(0.92)\end{array}$ & $(0.12-6.75)$ \\
\hline Pseudo $\mathrm{R}^{2}$ & .13 & & .09 & & .09 & & .08 & & .11 & & .14 & \\
\hline$n$ & 375 & & 375 & & 375 & & 375 & & 375 & & 375 & \\
\hline
\end{tabular}

Standard errors in parentheses. $* * * \mathrm{p}<0.001, * * \mathrm{p}<0.01, * \mathrm{p}<0.05,+\mathrm{p}<0.1$. CI $=$ Confidence intervals. OR $=$ Odds ratios.

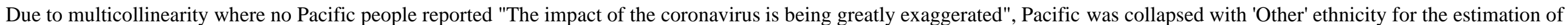
Model 6. 


\begin{tabular}{lrr}
\hline & $n$ & $\%$ \\
\hline All reasons why (W3, QE3a) & & \\
To stop me catching the coronavirus or getting very ill from it & 665 & 72.58 \\
To help allow my social and family life to get back to normal & 389 & 42.96 \\
To help allow my community to get back to normal & 523 & 55.99 \\
To help protect other people from catching the coronavirus & 591 & 66.12 \\
Because the vaccine won't work unless most people in New Zealand get it & 488 & 53.48 \\
Because I am a key worker working with high risk groups & 109 & 11.9 \\
Because I take the vaccines offered or recommended to me & 331 & 38.17 \\
Other (please specify) & 35 & 4.52 \\
Don't know & 11 & 1.65 \\
Prefer not to say & 4 & 0.37 \\
& & \\
Number of reasons & & \\
Gave no reason & 15 & 2.02 \\
1 reason & 243 & 25.46 \\
2 reasons & 82 & 9.31 \\
3 reasons & 109 & 12.20 \\
4 or more reasons & 460 & 51.01 \\
All reasons why (W3, QE3a) & & \\
To stop me catching the coronavirus or getting very ill from it & & \\
To help allow my social and family life to get back to normal & 367 & 39.36 \\
To help allow my community to get back to normal & 41 & 5.02 \\
To help protect other people from catching the coronavirus & 85 & 8.77 \\
Because the vaccine won't work unless most people in New Zealand get it & 154 & 16.61 \\
Because I am a key worker working with high risk groups & 148 & 17.02 \\
Because I take the vaccines offered or recommended to me & 42 & 4.78 \\
Other (please specify) & 28 & 2.83 \\
Don't know & 25 & 3.28 \\
Prefer not to say & 15 & 1.94 \\
\hline & 4 & 0.37 \\
\hline
\end{tabular}

Unweighted $n \mathrm{~s}$, weighted $\% \mathrm{~s}$. 


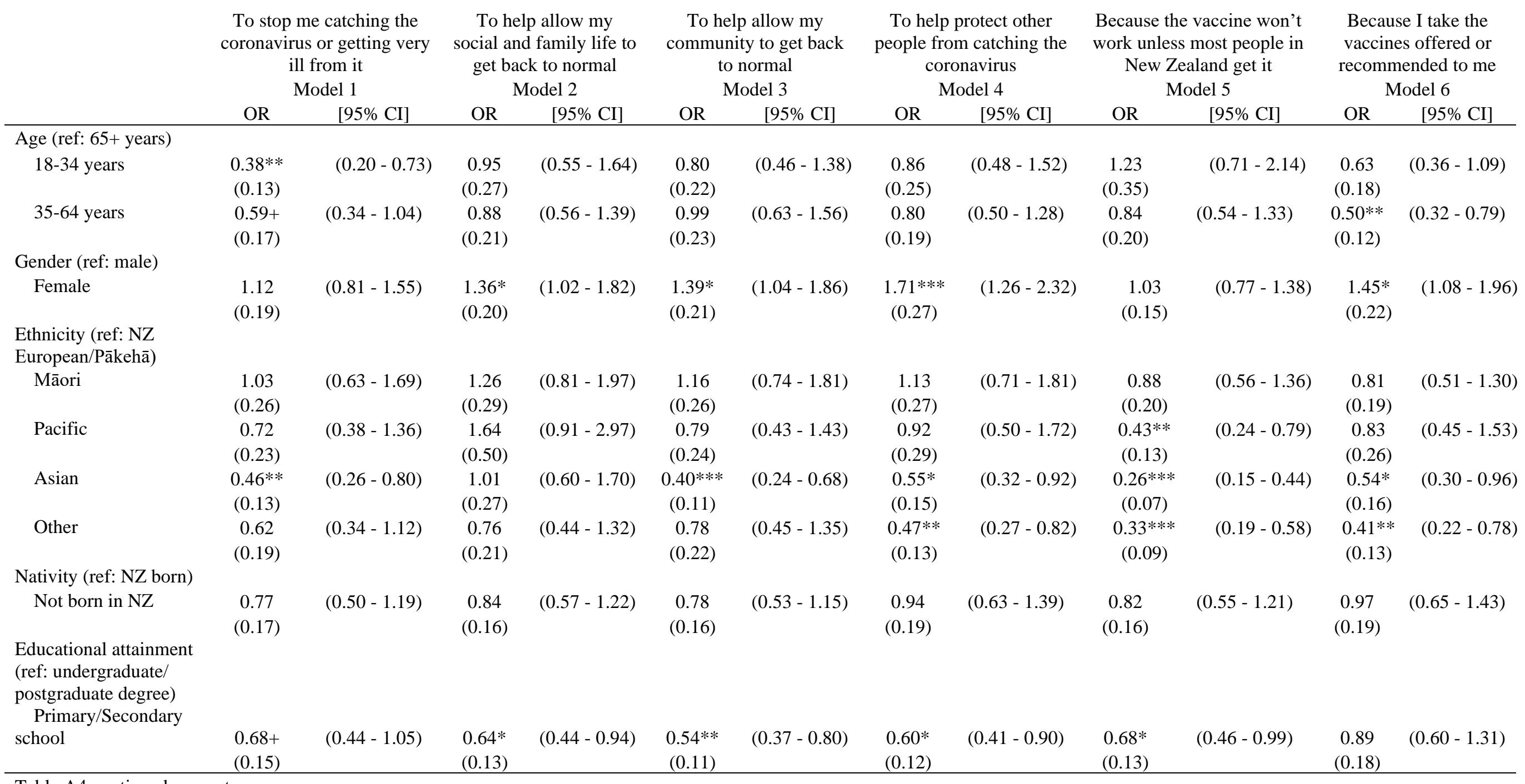

Table A4 continued on next page 
Table A4 continued

\begin{tabular}{|c|c|c|c|c|c|c|c|c|c|c|c|c|}
\hline Diploma & $\begin{array}{l}0.64 * \\
(0.13)\end{array}$ & $(0.43-0.95)$ & $\begin{array}{l}0.74+ \\
(0.13)\end{array}$ & $(0.52-1.05)$ & $\begin{array}{c}0.75 \\
(0.14)\end{array}$ & $(0.53-1.07)$ & $\begin{array}{c}0.75 \\
(0.14)\end{array}$ & $(0.52-1.08)$ & $\begin{array}{l}0.67 * \\
(0.12)\end{array}$ & $(0.47-0.95)$ & $\begin{array}{c}0.81 \\
(0.15)\end{array}$ & $(0.56-1.16)$ \\
\hline \multicolumn{13}{|l|}{$\begin{array}{l}\text { Annual household } \\
\text { income (ref: More than } \\
\$ 150,000)\end{array}$} \\
\hline$\$ 50,000$ or less & $\begin{array}{l}0.51^{*} \\
(0.17)\end{array}$ & $(0.27-0.97)$ & $\begin{array}{l}0.42 * * \\
(0.12)\end{array}$ & $(0.24-0.73)$ & $\begin{array}{l}0.41 * * \\
(0.12)\end{array}$ & $(0.23-0.72)$ & $\begin{array}{l}0.58+ \\
(0.17)\end{array}$ & $(0.32-1.04)$ & $\begin{array}{c}0.45^{* *} \\
(0.13)\end{array}$ & $(0.25-0.79)$ & $\begin{array}{l}0.61+ \\
(0.18)\end{array}$ & $(0.35-1.08)$ \\
\hline$\$ 50,001-\$ 70,000$ & $\begin{array}{c}0.69 \\
(0.22)\end{array}$ & $(0.37-1.29)$ & $\begin{array}{l}0.54 * \\
(0.15)\end{array}$ & $(0.31-0.93)$ & $\begin{array}{l}0.62+ \\
(0.17)\end{array}$ & $(0.36-1.07)$ & $\begin{array}{c}0.77 \\
(0.22)\end{array}$ & $(0.43-1.36)$ & $\begin{array}{c}0.47 * * \\
(0.13)\end{array}$ & $(0.27-0.82)$ & $\begin{array}{c}0.93 \\
(0.26)\end{array}$ & $(0.54-1.62)$ \\
\hline$\$ 70,001-\$ 100,000$ & $\begin{array}{c}0.64 \\
(0.19)\end{array}$ & $(0.36-1.14)$ & $\begin{array}{l}0.58^{*} \\
(0.15)\end{array}$ & $(0.35-0.95)$ & $\begin{array}{l}0.53^{*} \\
(0.14)\end{array}$ & $(0.32-0.89)$ & $\begin{array}{c}0.66 \\
(0.18)\end{array}$ & $(0.39-1.12)$ & $\begin{array}{c}0.40 * * * \\
(0.10)\end{array}$ & $(0.24-0.67)$ & $\begin{array}{c}0.72 \\
(0.19)\end{array}$ & $(0.43-1.20)$ \\
\hline$\$ 100,001-\$ 150,000$ & $\begin{array}{c}0.68 \\
(0.19)\end{array}$ & $(0.39-1.19)$ & $\begin{array}{c}0.48^{* *} \\
(0.12)\end{array}$ & $(0.30-0.78)$ & $\begin{array}{c}0.67 \\
(0.17)\end{array}$ & $(0.41-1.10)$ & $\begin{array}{l}0.61+ \\
(0.16)\end{array}$ & $(0.36-1.02)$ & $\begin{array}{c}0.51 * * \\
(0.13)\end{array}$ & $(0.31-0.85)$ & $\begin{array}{c}0.76 \\
(0.19)\end{array}$ & $(0.47-1.25)$ \\
\hline \multicolumn{13}{|l|}{$\begin{array}{l}\text { Family structure (ref: } \\
\text { Two parents, } \\
\text { dependent children) }\end{array}$} \\
\hline Single parent & $\begin{array}{c}0.71 \\
(0.27)\end{array}$ & $(0.34-1.50)$ & $\begin{array}{c}1.60 \\
(0.59)\end{array}$ & $(0.78-3.31)$ & $\begin{array}{c}1.00 \\
(0.38)\end{array}$ & $(0.48-2.09)$ & $\begin{array}{c}1.02 \\
(0.39)\end{array}$ & $(0.48-2.15)$ & $\begin{array}{c}1.07 \\
(0.40)\end{array}$ & $(0.51-2.24)$ & $\begin{array}{c}0.94 \\
(0.39)\end{array}$ & $(0.42-2.11)$ \\
\hline Living alone & $\begin{array}{c}0.99 \\
(0.29)\end{array}$ & $(0.56-1.76)$ & $\begin{array}{c}0.84 \\
(0.23)\end{array}$ & $(0.49-1.44)$ & $\begin{array}{c}0.93 \\
(0.25)\end{array}$ & $(0.55-1.57)$ & $\begin{array}{c}0.87 \\
(0.24)\end{array}$ & $(0.51-1.50)$ & $\begin{array}{c}1.08 \\
(0.29)\end{array}$ & $(0.64-1.84)$ & $\begin{array}{c}0.78 \\
(0.22)\end{array}$ & $(0.44-1.37)$ \\
\hline $\begin{array}{l}\text { Partner, no } \\
\text { dependent children }\end{array}$ & $\begin{array}{c}1.34 \\
(0.27)\end{array}$ & $(0.90-1.97)$ & $\begin{array}{c}1.02 \\
(0.19)\end{array}$ & $(0.72-1.46)$ & $\begin{array}{c}0.99 \\
(0.18)\end{array}$ & $(0.69-1.41)$ & $\begin{array}{c}0.94 \\
(0.18)\end{array}$ & $(0.65-1.35)$ & $\begin{array}{l}1.02 \\
(0.19)\end{array}$ & $(0.71-1.46)$ & $\begin{array}{c}1.22 \\
(0.23)\end{array}$ & $(0.84-1.76)$ \\
\hline Other & $\begin{array}{c}1.40 \\
(0.38)\end{array}$ & $(0.82-2.40)$ & $\begin{array}{c}1.21 \\
(0.30)\end{array}$ & $(0.75-1.96)$ & $\begin{array}{c}1.14 \\
(0.28)\end{array}$ & $(0.70-1.86)$ & $\begin{array}{c}1.22 \\
(0.32)\end{array}$ & $(0.73-2.02)$ & $\begin{array}{c}0.79 \\
(0.20)\end{array}$ & $(0.49-1.29)$ & $\begin{array}{c}0.97 \\
(0.25)\end{array}$ & $(0.58-1.61)$ \\
\hline \multicolumn{13}{|l|}{$\begin{array}{l}\text { Work status (ref: } \\
\text { employed) }\end{array}$} \\
\hline Unemployed & $\begin{array}{c}1.07 \\
(0.39)\end{array}$ & $(0.53-2.18)$ & $\begin{array}{c}1.06 \\
(0.36)\end{array}$ & $(0.54-2.08)$ & $\begin{array}{c}1.24 \\
(0.42)\end{array}$ & $(0.63-2.41)$ & $\begin{array}{c}0.80 \\
(0.27)\end{array}$ & $(0.41-1.56)$ & $\begin{array}{c}1.31 \\
(0.44)\end{array}$ & $(0.67-2.53)$ & $\begin{array}{c}0.91 \\
(0.34)\end{array}$ & $(0.44-1.90)$ \\
\hline Not working & $\begin{array}{l}1.71^{*} \\
(0.44)\end{array}$ & $(1.03-2.85)$ & $\begin{array}{c}1.21 \\
(0.27)\end{array}$ & $(0.78-1.88)$ & $\begin{array}{l}1.65 * \\
(0.37)\end{array}$ & $(1.06-2.57)$ & $\begin{array}{c}1.12 \\
(0.26)\end{array}$ & $(0.71-1.77)$ & $\begin{array}{l}1.07 \\
(0.24)\end{array}$ & $(0.69-1.65)$ & $\begin{array}{c}1.39 \\
(0.32)\end{array}$ & $(0.89-2.18)$ \\
\hline
\end{tabular}

Table A4 continued on next page 


\begin{tabular}{|c|c|c|c|c|c|c|c|c|c|c|c|c|}
\hline \multicolumn{13}{|l|}{ Region (ref: Auckland) } \\
\hline \multicolumn{13}{|l|}{ Bay of Plenty and } \\
\hline Eastern North Island & $\begin{array}{c}0.76 \\
(0.22)\end{array}$ & $(0.43-1.35)$ & $\begin{array}{c}1.13 \\
(0.29)\end{array}$ & $(0.68-1.88)$ & $\begin{array}{c}0.80 \\
(0.21)\end{array}$ & $(0.47-1.34)$ & $\begin{array}{c}0.90 \\
(0.24)\end{array}$ & $(0.53-1.52)$ & $\begin{array}{c}0.74 \\
(0.20)\end{array}$ & $(0.44-1.24)$ & $\begin{array}{c}1.28 \\
(0.35)\end{array}$ & $(0.75-2.19)$ \\
\hline \multicolumn{13}{|l|}{ Canterbury and } \\
\hline Tasman & $\begin{array}{c}1.03 \\
(0.24)\end{array}$ & $(0.65-1.62)$ & $\begin{array}{l}0.62 * \\
(0.13)\end{array}$ & $(0.41-0.93)$ & $\begin{array}{c}0.87 \\
(0.18)\end{array}$ & $(0.58-1.32)$ & $\begin{array}{c}1.11 \\
(0.24)\end{array}$ & $(0.72-1.69)$ & $\begin{array}{c}1.20 \\
(0.25)\end{array}$ & $(0.79-1.81)$ & $\begin{array}{l}1.49+ \\
(0.32)\end{array}$ & $(0.98-2.27)$ \\
\hline Northland & $\begin{array}{c}1.19 \\
(0.59)\end{array}$ & $(0.45-3.12)$ & $\begin{array}{c}0.76 \\
(0.30)\end{array}$ & $(0.35-1.65)$ & $\begin{array}{c}0.66 \\
(0.26)\end{array}$ & $(0.31-1.43)$ & $\begin{array}{c}1.44 \\
(0.64)\end{array}$ & $(0.61-3.44)$ & $\begin{array}{c}1.47 \\
(0.60)\end{array}$ & $(0.66-3.28)$ & $\begin{array}{c}1.00 \\
(0.41)\end{array}$ & $(0.45-2.21)$ \\
\hline Southland & $\begin{array}{c}0.96 \\
(0.33)\end{array}$ & $(0.48-1.89)$ & $\begin{array}{l}0.54+ \\
(0.18)\end{array}$ & $(0.28-1.02)$ & $\begin{array}{l}0.59+ \\
(0.18)\end{array}$ & $(0.32-1.09)$ & $\begin{array}{c}0.99 \\
(0.32)\end{array}$ & $(0.53-1.87)$ & $\begin{array}{c}0.72 \\
(0.23)\end{array}$ & $(0.39-1.34)$ & $\begin{array}{c}0.72 \\
(0.25)\end{array}$ & $(0.37-1.42)$ \\
\hline Waikato and mid- & & & & & & & & & & & & \\
\hline North Island & $\begin{array}{c}0.96 \\
(0.23)\end{array}$ & $(0.60-1.54)$ & $\begin{array}{c}0.71 \\
(0.15)\end{array}$ & $(0.47-1.07)$ & $\begin{array}{c}0.57 * * \\
(0.12)\end{array}$ & $(0.38-0.87)$ & $\begin{array}{c}0.87 \\
(0.19)\end{array}$ & $(0.57-1.34)$ & $\begin{array}{c}1.09 \\
(0.23)\end{array}$ & $(0.71-1.66)$ & $\begin{array}{c}1.08 \\
(0.24)\end{array}$ & $(0.70-1.66)$ \\
\hline Wellington & $\begin{array}{c}0.90 \\
(0.23)\end{array}$ & $(0.54-1.49)$ & $\begin{array}{l}0.65+ \\
(0.15)\end{array}$ & $(0.41-1.03)$ & $\begin{array}{l}0.67+ \\
(0.16)\end{array}$ & $(0.43-1.06)$ & $\begin{array}{c}0.97 \\
(0.23)\end{array}$ & $(0.60-1.55)$ & $\begin{array}{c}0.88 \\
(0.21)\end{array}$ & $(0.56-1.40)$ & $\begin{array}{c}1.30 \\
(0.31)\end{array}$ & $(0.82-2.07)$ \\
\hline Constant & $\begin{array}{c}9.47 * * * \\
(3.97)\end{array}$ & $(4.17-21.52)$ & $\begin{array}{l}2.03 * \\
(0.70)\end{array}$ & $(1.03-4.00)$ & $\begin{array}{c}4.04 * * * \\
(1.44)\end{array}$ & $(2.01-8.14)$ & $\begin{array}{c}3.92 * * * \\
(1.43)\end{array}$ & $(1.91-8.03)$ & $\begin{array}{c}4.65 * * * \\
(1.67)\end{array}$ & $(2.30-9.39)$ & $\begin{array}{c}1.08 \\
(0.38)\end{array}$ & $(0.54-2.16)$ \\
\hline Pseudo $\mathrm{R}^{2}$ & .05 & & .04 & & .04 & & .04 & & .06 & & .06 & \\
\hline$n$ & 909 & & 909 & & 909 & & 909 & & 909 & & 909 & \\
\hline
\end{tabular}

Standard errors in parentheses. $* * * \mathrm{p}<0.001, * * \mathrm{p}<0.01, * \mathrm{p}<0.05,+\mathrm{p}<0.1 . \mathrm{CI}=$ Confidence intervals. OR $=$ Odds ratios. 